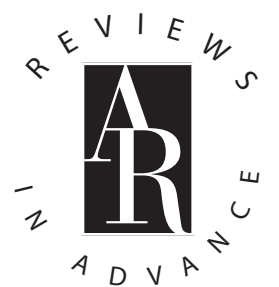

Review in Advance first posted online on May 13, 2015. (Changes may still occur before final publication online and in print.)

\title{
Itaconic Acid: The Surprising Role of an Industrial Compound as a Mammalian Antimicrobial Metabolite
}

\author{
Thekla Cordes, ${ }^{1,2, *}$ Alessandro Michelucci, ${ }^{1, *}$ \\ and Karsten Hiller ${ }^{1}$
}

${ }^{1}$ Luxembourg Centre for Systems Biomedicine, University of Luxembourg, L-4362 Esch-Belval, Luxembourg; email: thekla.cordes@uni.lu, alessandro.michelucci@uni.lu, karsten.hiller@uni.lu

${ }^{2}$ Current address: Department of Bioengineering, University of California, San Diego, La Jolla, California 92093-0412; email: tcordes@eng.ucsd.edu

Annu. Rev. Nutr. 2015. 35:12.1-12.23

The Annual Review of Nutrition is online at nutr.annualreviews.org

This article's doi:

10.1146/annurev-nutr-071714-034243

Copyright (C) 2015 by Annual Reviews. All rights reserved

${ }^{*}$ Equal contributors

\section{Keywords}

metabolism, immune-responsive gene 1 protein (IRG1), macrophage, cis-aconitic acid decarboxylase, metabolic immunity, inflammation

\begin{abstract}
Itaconic acid is well known as a precursor for polymer synthesis and has been involved in industrial processes for decades. In a recent surprising discovery, itaconic acid was found to play a role as an immune-supportive metabolite in mammalian immune cells, where it is synthesized as an antimicrobial compound from the citric acid cycle intermediate $c i s$-aconitic acid. Although the immune-responsive gene 1 protein (IRG1) has been associated to immune response without a mechanistic function, the critical link to itaconic acid production through an enzymatic function of this protein was only recently revealed. In this review, we highlight the history of itaconic acid as an industrial and antimicrobial compound, starting with its biotechnological synthesis and ending with its antimicrobial function in mammalian immune cells.
\end{abstract}




\section{Contents}

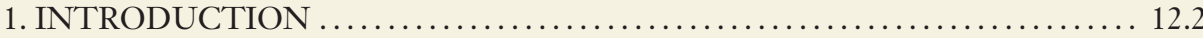

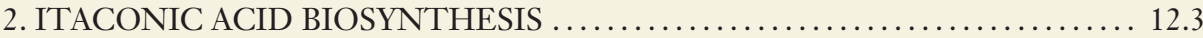

2.1. The Beginning of Itaconic Acid Production ......................... 12.3

2.2. Itaconic Acid Metabolism in A. terreus . . . . . . . . . . . . . . . . . . . . 12.3

2.3. Subcellular Compartmentalization of Itaconic Acid

Biosynthesis in $A$. terreus . . . . . . . . . . . . . . . . . . . . . . . . 12.5

3. INDUSTRIAL PRODUCTION OF ITACONIC ACID $\ldots \ldots \ldots \ldots \ldots \ldots \ldots \ldots \ldots \ldots \ldots \ldots \ldots \ldots$

4. ANTIMICROBIAL ACTIVITY OF ITACONIC ACID $\ldots \ldots \ldots \ldots \ldots \ldots \ldots \ldots \ldots \ldots \ldots \ldots \ldots$

4.1. Itaconic Acid Inhibits the Glyoxylate Shunt .................... 12.7

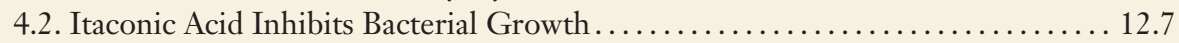

4.3. Itaconic Acid Inhibits the Citramalate Cycle . . . . . . . . . . . . . . . . . 12.9

4.4. Bacteria Detoxify Itaconic Acid . . . . . . . . . . . . . . . . . . . . . 12.9

5. ITACONIC ACID AND MAMMALIAN METABOLISM $\ldots \ldots \ldots \ldots \ldots \ldots \ldots \ldots \ldots \ldots \ldots \ldots \ldots \ldots .12 .10$

5.1. The Discovery of Itaconic Acid and CAD Activity in Mammalian Cells....... 12.10

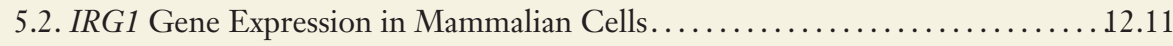

5.3. IRG1 Posttranscriptional Stability and CAD/IRG1 Regulation .............12.12

5.4. Subcellular Localization of Mammalian CAD/IRG1 .................... 12.12

5.5. Itaconic Acid Secretion and Metabolism in Mammalian Cells .................12.13

5.6. Itaconic Acid Affects Energy Metabolism ................................ 12.13

6. THE EMERGING CONCEPT OF METABOLIC IMMUNITY: THE INTERPLAY AMONG IMMUNITY, INFLAMMATION,

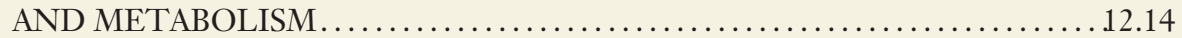

6.1. Metabolic Shifts in Immune Cells During Inflammation ................. 12.14

6.2. Metabolites as Antimicrobial Effectors and Inflammatory Signals.......... 12.15

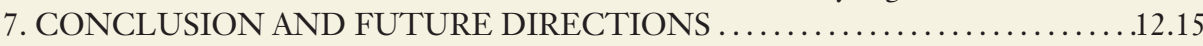

Aspergillus terreus and Aspergillus itaconicus: soil fungi commonly used for biotechnological itaconic acid production TCA: tricarboxylic acid

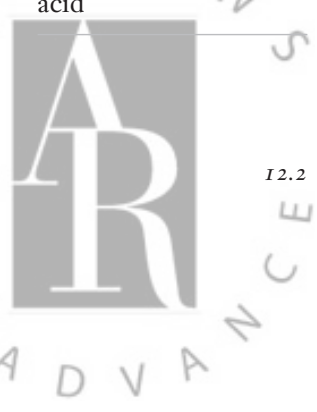

\section{INTRODUCTION}

Itaconic acid (also known as methylene succinic acid) is an organic, unsaturated dicarboxylic acid that plays an important role in immunity as well as in industrial biotechnology. Itaconic acid is of high interest for industry because the double bond of its methylene group makes this metabolite useful for polymer synthesis. The biotechnological production of itaconic acid was established in the 1960s, and the compound is currently produced by the fungus Aspergillus terreus. However, industrial companies are still interested in optimizing the production process to satisfy the increasing demand for itaconic acid for widespread applications $(47,72)$.

In a recent surprising discovery, itaconic acid biosynthesis was found in mammalian immune cells and has been linked to inflammation (91). Immune cells, such as macrophages and dendritic cells, are known to undergo a drastic metabolic change during inflammatory processes. However, the mammalian synthesis of itaconic acid could not be explained by a known mammalian metabolic pathway, and up until 2013, no enzymatic reaction for its production had been described (89).

In 2013, the mammalian metabolic pathway for itaconic acid biosynthesis was revealed: In mammals, itaconic acid is produced by the decarboxylation of cis-aconitic acid, a tricarboxylic acid (TCA) cycle intermediate, by immune-responsive gene 1 protein (IRG1) encoded by immunoresponsive gene 1 ( $\operatorname{Irg} 1)(64)$. It has been known for decades that this gene is highly upregulated in

Cordes $\bullet$ Michelucci $\bullet$ Hiller 
mammalian macrophages under proinflammatory conditions, such as bacterial infections. But the catalytic function of IRG1 protein and the important role of itaconic acid during inflammation were only recently discovered.

Itaconic acid acts as an endogenously formed antimicrobial compound that contributes, together with several other inflammatory metabolites and cytokines, to an efficient immune response. However, invading pathogens have developed a defense strategy against itaconic acid, degrading and detoxifying this antimicrobial compound $(63,81)$.

Several reviews on itaconic acid production have been published $(26,47,72,106)$, but all lack a focus on its mammalian biosynthesis. The present review summarizes the industrial production and related fungal metabolism of itaconic acid and highlights its antimicrobial role against pathogens during inflammation. In this context, we provide a broad overview on IRG1 and the metabolism of itaconic acid in mammalian cells to account for its importance in the emerging concept of metabolic immunity.

\section{ITACONIC ACID BIOSYNTHESIS}

\subsection{The Beginning of Itaconic Acid Production}

In 1836, Baup discovered the formation of an unknown compound during distillation of citric acid (4). In 1840, Crasso synthesized the same compound by decarboxylation of cis-aconitic acid and introduced its current name, itaconic acid, which represents an anagram of cis-aconitic acid (98).

Almost 100 years later, in 1931, itaconic acid was found for the first time to be produced in vivo by the fungus Aspergillus itaconicus, which has been descriptively named thereafter (46). To date, several other natural producers of itaconic acid were identified, such as Aspergillus terreus (12), Ustilago zeae (38), and Ustilago maydis and the yeast Candida sp. (93). In 2011, Sugimoto et al. (91) discovered that mammalian immune cells are also able to synthesize itaconic acid (see Section 5).

\subsection{Itaconic Acid Metabolism in A. terreus}

Although itaconic acid continued to be of high interest for industrial applications, the exact metabolic precursor for its biosynthesis in $A$. terreus was not clarified for many years. Three different pathways were postulated, including its formation from cis-aconitic acid, from citramalic acid, or from 1,2,3-tricarboxypropane. All of these biosynthetic pathways are based on the catabolism of sugars to pyruvic acid and acetyl-CoA as potential precursors for itaconic acid synthesis (9).

In 1957, Bentley \& Thiessen $(5,6)$ proposed the formation of itaconic acid from the TCA cycle intermediate $c i$-aconitic acid. The authors hypothesized that itaconic acid is produced through a decarboxylation catalyzed by the enzyme cis-aconitic acid decarboxylase (CAD), which is encoded by the gene $c a d A$. Later, isotope tracing experiments using labeled carbon substrates confirmed this proposed pathway (9).

Essential for itaconic acid production is the catalytic activity of aconitase, an enzyme catalyzing the formation of the precursor cis-aconitic acid from citric acid (42). It has been shown that the enzymatic activity, as well as the transcriptional level of aconitase, is elevated during itaconic acid formation (42). Surprisingly, the inhibition of aconitase using the toxic chemical fluoroacetate (31, 110) does not affect itaconic acid production in A. terreus (5).

As a carbon source for itaconic acid production, the fungus takes up glucose from the extracellular environment and metabolizes it into itaconic acid. The breakdown of one molecule of glucose leads to two molecules of pyruvic acid: One molecule is further converted to acetyl-CoA through oxidative decarboxylation catalyzed by pyruvate dehydrogenase, while the

www.annualreviews.org • Itaconic Acid as a Mammalian Antimicrobial Metabolite
CAD: cis-aconitic acid decarboxylase

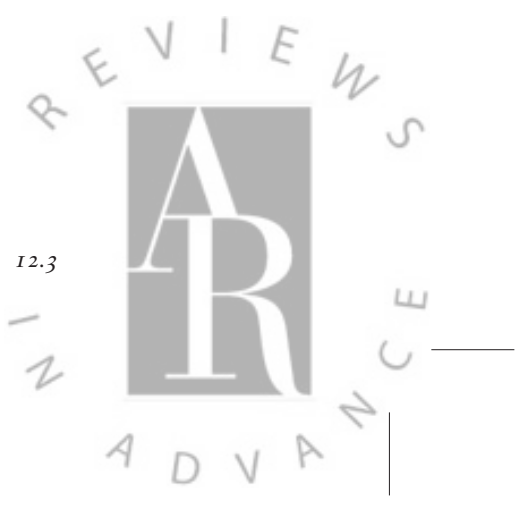


other molecule is converted in the cytosol to oxaloacetic acid catalyzed by the anaplerotic enzyme pyruvate carboxylase. In contrast to its mitochondrial location in mammals, pyruvate carboxylase is present in the cytosol in A. terreus. $\mathrm{CO}_{2}$, which is needed for the carboxylation of pyruvic acid, could be derived either from cis-aconitic acid decarboxylase or pyruvate dehydrogenase activity. Oxaloacetic acid is reduced to malic acid, which is transported into the mitochondria where it is reoxidized to oxaloacetic acid (see Figure 1) (7, 47). In addition to CAD and aconitase, another enzyme required for itaconic acid production is citrate synthase. This enzyme catalyzes the condensation of acetyl-CoA and oxaloacetic acid to form citric acid. Aconitase further dehydrates citric acid to cis-aconitic acid, the direct precursor of itaconic acid. As the last step for itaconic acid production, CAD decarboxylizes cis-aconitic acid to itaconic acid (see Figure 1).

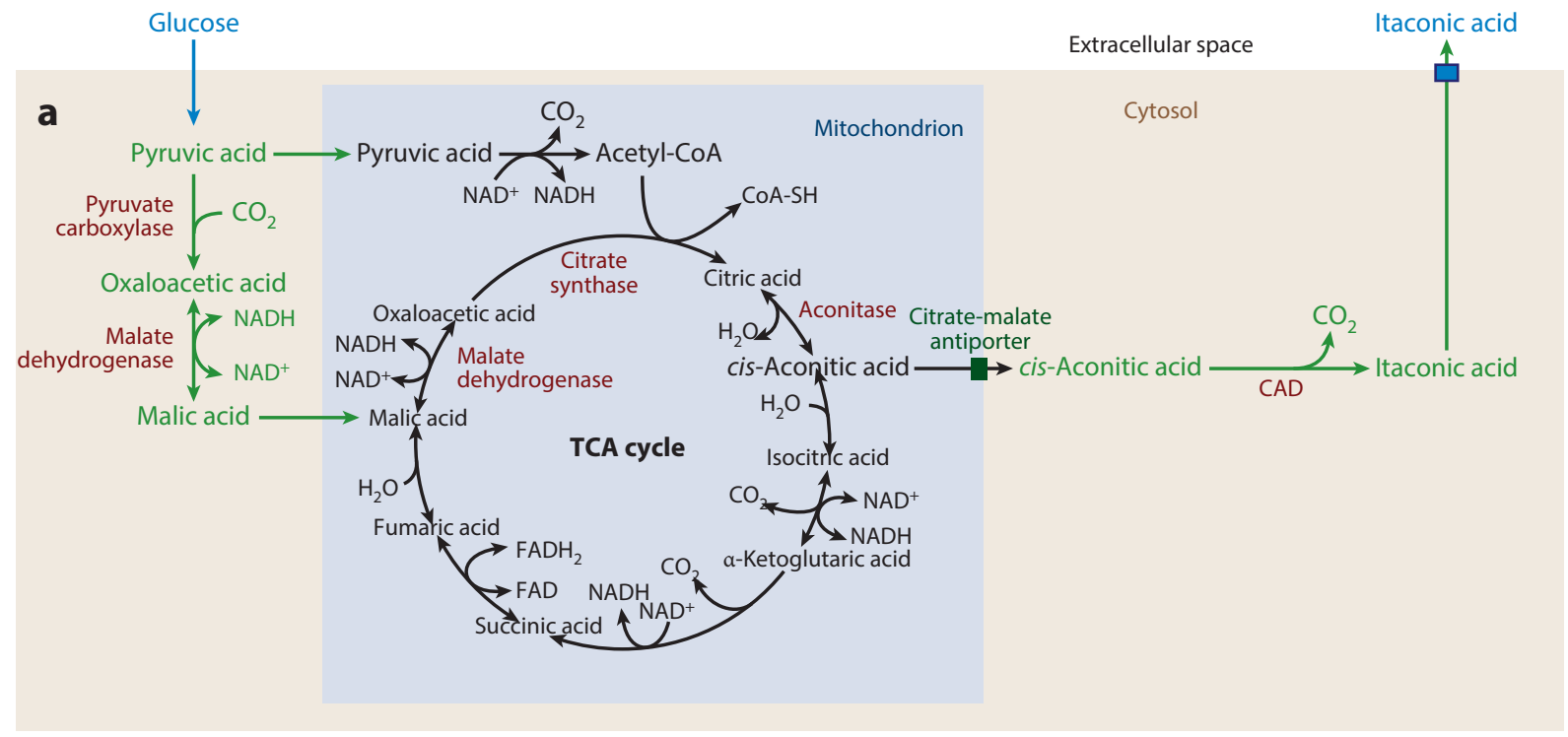

b<smiles>O=C(O)CC(O)C(=O)O</smiles><smiles>CC(C)[C@H](O)C(C)O</smiles>

Citric acid

$$
\begin{aligned}
& \mathrm{C}-\mathrm{COOH} \\
& \mathrm{HC}-\mathrm{COOH}
\end{aligned}
$$

cis-Aconitic acid

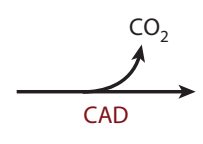<smiles>C=CCC(=O)O</smiles>

Itaconic acid

Figure 1

Biosynthesis of itaconic acid production and its subcellular localization in Aspergillus terreus. Glucose, as a substrate for itaconic acid formation, is converted through glycolysis into pyruvic acid in the cytosol. Pyruvic acid enters the tricarboxylic acid (TCA) cycle in the mitochondria either via acetyl-CoA or malic acid. The TCA cycle intermediate cis-aconitic acid is transported from the mitochondria into the cytosol, possibly through the citrate-malate antiporter (green box), and serves as a precursor for itaconic acid production catalyzed by cis-áconitic acid decarboxylase (CAD). Finally, itaconic acid is further secreted into the medium through an unknown transport mechanism (blue box). Extracellular metabolites are marked in blue; cytosolic metabolites, green; mitochondrial metabolites, black; and involved enzymes, red. Abbreviations: $\mathrm{FAD}$, flavin adenine dinucleotide; $\mathrm{FADH}_{2}$, reduced form of flavin adenine dinucleotide; NADH, reduced form of nicotinamide adenine dinucleotide; NAD+, oxidized form of nicotinamide adenine dinucleotide. disteotid

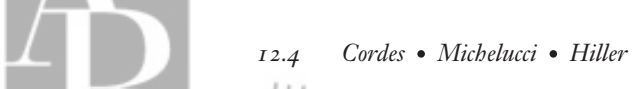


To understand the regulation of itaconic acid production, Bonnarme et al. (9) compared the regulation of itaconic acid production in $A$. terreus with that of citric acid production in $A$. niger. The authors showed that during itaconic acid synthesis, the concentrations of pyruvic acid, oxaloacetic acid, and citric acid were increased. Since the same metabolites also show increased levels during citric acid production in $A$. niger, they speculated a similar regulation for itaconic acid production in $A$. terreus. Mechanistically, oxaloacetic acid inhibits $\alpha$-ketoglutarate dehydrogenase while it stimulates the condensation of acetyl-CoA and oxaloacetic acid to form citric acid, catalyzed by citrate synthase (9). It is so far not clear whether itaconic acid production is exclusively initiated by this mechanism or by additional as-yet-unknown regulatory mechanisms, especially when considering the subcellular compartmentalization of itaconic acid synthesis.

\subsection{Subcellular Compartmentalization of Itaconic Acid Biosynthesis in $A$. terreus}

In $A$. terreus, CAD is localized in the cytosol, and consequently, this is the location of itaconic acid production. However, its direct precursor, cis-aconitic acid, is synthesized in mitochondria. Citrate synthase, the enzyme that catalyzes the condensation of acetyl-CoA and oxaloacetic acid to form citric acid, is exclusively present in mitochondria. Moreover, the reaction from citric acid to cis-aconitic acid, catalyzed by aconitase, also operates in mitochondria (42).

As a consequence, a transport of cis-aconitic acid or citric acid from mitochondria into the cytosol is required (see Figure 1). Jaklisch et al. (42) postulated that cis-aconitic acid is translocated from the mitochondria into the cytosol via a citrate-malate antiporter. However, the exact transport mechanism is still unknown, and it is possible that other carrier systems are involved in cis-aconitic acid translocation (42). To this end, a putative mitochondrial carrier protein that is encoded by a gene located directly upstream of the $c a d A$ gene was identified, supporting the likelihood that this carrier protein is indeed involved in cis-aconitic acid shuttling into the cytosol (88).

Finally, a secretion mechanism for itaconic acid is required because $A$. terreus accumulates itaconic acid in the extracellular environment (88). However, potential transporters involved are not yet known. Considering that itaconic acid is secreted in large amounts by $A$. terreus, it can be hypothesized that the compound is not further metabolized by this fungus and may have other functions. As we discuss in Section 4, itaconic acid is an antimicrobial compound, and based on this knowledge, it is possible that $A$. terreus produces and secretes itaconic acid to combat against competing microbes.

\section{INDUSTRIAL PRODUCTION OF ITACONIC ACID}

The discovery of itaconic acid has been of growing interest for industry because of its potential role as a replacement for crude oil-based products, such as acrylic acid. The chemical structure of itaconic acid, with its reactive methylene group, enables a self-polymerization to polyitaconic acid (88). Therefore, itaconic acid is industrially used as a precursor for plastic polymer synthesis as well as for resins, lattices, and fibers (for reviews, see 26, 72, 106).

Currently, the annual global production capacity of itaconic acid is approximately 40,000 tons, with one kilogram costing 1.5-2.5 USD (47). To satisfy the increasing demand of itaconic acid for widespread applications, industrial-scale production of itaconic acid is required. Because distillation of citric acid leads to low itaconic acid yields, itaconic acid is currently mainly biotechnologically produced through a fermentation process by the fungus $A$. terreus $(9,72)$.

The first industrial itaconic acid production process was established in the United States in 1945 by Charles Pfizer Co., which owned the patent for fermentative itaconic acid production.

www.annualreviews.org • Itaconic Acid as a Mammalian Antimicrobial Metabolite
Acrylic acid: the simplest unsaturated carboxylic acid, consisting of a vinyl group connected directly to a carboxylic terminus

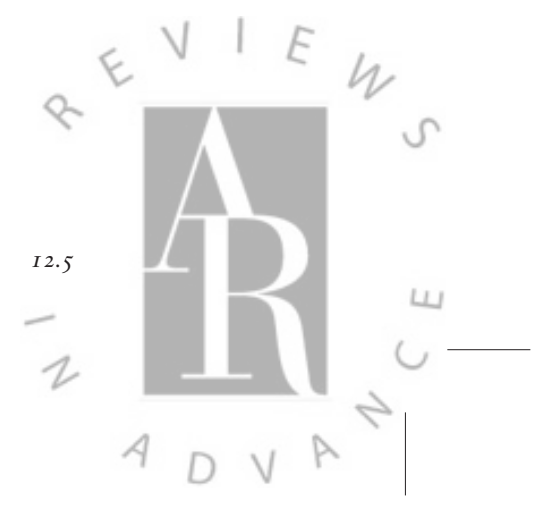


Subsequently, manufacturers from Europe, China, and Japan followed (106). Currently, A. terreus is used in batch processes at temperatures around $37^{\circ} \mathrm{C}$, with glucose, or cheaper pretreated starch materials, as substrates for commercial itaconic acid production. The fermentation process occurs under phosphate-limiting growth conditions (106) and in an acidic environment (52).

The biosynthetic and process parameters of itaconic acid formation are well described and have been established since the 1960s; this topic is broad enough for its own review and is not discussed here. Instead, we refer readers to previously published reviews by Okabe et al. (72), Willke \& Vorlop (106), Klement \& Büchs (47), and El-Imam \& Du (26).

Although $A$. terreus produces up to $86 \mathrm{~g} \cdot \mathrm{l}^{-1}$ of itaconic acid, industrial companies are interested in further optimizing the production process. This includes the increase of space-time yield and final product concentration, as well as the utilization of cheaper substrates to make the process even more economical (47).

As an example of economization, Bressler \& Braun (11) have investigated an itaconic acid production process in a membrane reactor using citric acid as a precursor, which is about onetenth the cost of itaconic acid. In addition to the use of conventional batch processes, production of itaconic acid was investigated with immobilized $A$. terreus in continuous processes, which have been shown to increase spatiotemporal yields (44).

However, efficient itaconic acid production using filamentous fungi has certain drawbacks. For example, fermentative itaconic acid production by the fungus $A$. terreus is strictly aerobic because low oxygen concentrations damage the mycelia and affect fungal metabolism due to low adenosine triphosphate (ATP) production $(34,106)$. In addition, oxygen supply is required for the oxidation of the reduced form of nicotine adenine dinucleotide (NADH) to regenerate the cofactor $\mathrm{NAD}^{+}$(oxidized form of NAD). High NADH levels inhibit important enzymes, including citrate synthase and phosphofructokinase, which are involved in itaconic acid production (47). Thus, the production process requires continuous aeration and high power input with high stirring intensities, resulting in increased mechanical stress that damages the mycelia. To overcome this drawback, an itaconic acid production process in air-lift bioreactors, containing draft tubes instead of stirrers, was developed to increase production rates $(73,108)$. Another promising idea is based on the use of an engineered $A$. terreus expressing a hemoglobin gene from the aerobic bacterium Vitreoscilla to reduce oxygen dependency and to increase itaconic acid formation (56).

Because the itaconic acid production process is sensitive to several medium components (106), media optimization is of high importance. For that purpose, small-scale screenings in scaled-down models, e.g., microtiter plates, have been developed to circumvent costly optimization procedures in bioreactors (39).

It has also been reported that itaconic acid itself inhibits the growth of $A$. terreus and, in turn, suppresses the formation of itaconic acid. Such product inhibition can be overcome by using mutant strains that are more resistant to itaconic acid (109). Because itaconic acid does not alter the gene expression of $c a d A(43)$, itaconic acid possibly alters CAD activity. Therefore, more detailed research on the exact mechanism of itaconic acid feedback inhibition is required.

Another strategy to increase itaconic acid yields is in taking advantage of other host organisms, such as $A$. niger, a strain that is known to produce up to $200 \mathrm{~g} \cdot \mathrm{1}^{-1}$ citric acid. Due to the lack of a cis-aconitic acid decarboxylating enzyme, the $c a d A$ gene of $A$. terreus was engineered into $A$. niger. However, compared to the citric acid synthesis capacity, very low itaconic acid concentrations $\left(0.05 \mathrm{~g} \cdot \mathrm{l}^{-1}\right)$ were achieved. Only concomitant overexpression of a mitochondrial transporter $(m t t A)$ in combination with a plasma membrane transporter $(m f s A)$ led to a 20 -fold increased yield compared to the overexpression of $c a d A$ alone (101). The authors of this article suggest that MfsA is a membrane transporter required for itaconic acid secretion (for more details on subcellular compartmentalization of itaconic acid biosynthesis, see Section 2). The optimization

Cordes $\bullet$ Michelucci $\bullet$ Hiller 
of the fermentation process using the natural itaconic acid producer Ustilago maydis only achieved, with $44.5 \mathrm{~g} \cdot \mathrm{l}^{-1}$ of itaconic acid, half of the production of $A$. terreus (57).

For increasing itaconic acid yields, the kinetic parameters and the low stability of CAD enzyme need to be considered. To compensate for the low stability of CAD enzyme, strains overproducing itaconic acid require a high mRNA level of $c a d A$ (109). For the same reason, the enzymatic characterization of fungal CAD is challenging and is one of the reasons why the enzymatic properties of this enzyme in $A$. terreus have only been recently described by Dwiarti et al. (25). The authors showed that the fungal CAD enzyme has a molecular mass of $55 \mathrm{kD}$ and determined the Michaelis-Menten constant $\left(\mathrm{K}_{\mathrm{M}}\right)$ for the substrate cis-aconitic acid at $\mathrm{pH}=6.2$ and $37^{\circ} \mathrm{C}$ as $\mathrm{K}_{\mathrm{M}}=2.45 \mathrm{mmol} \cdot \mathrm{1}^{-1}(25)$. Based on the high $\mathrm{K}_{\mathrm{M}}$ value, CAD has a low affinity to the itaconic acid precursor cis-aconitic acid, and thus high substrate levels are required to reach maximal itaconic acid production. Supplementation of cis-aconitic acid into the growth medium in combination with an engineered $A$. terreus strain that has the ability to transport cis-aconitic acid from the extracellular environment into the cytosol could be beneficial in increasing itaconic acid production.

Despite the use of different strategies to optimize itaconic acid yields, none has achieved higher production rates than fermentation by $A$. terreus. Therefore, fermentation by this fungus is still the dominant commercial process used for itaconic acid production. However, the high interest in process optimization could lead to a future replacement of $A$. terreus by a different organism as the main itaconic acid producer (47).

\section{ANTIMICROBIAL ACTIVITY OF ITACONIC ACID}

\subsection{Itaconic Acid Inhibits the Glyoxylate Shunt}

Itaconic acid plays an important role as a bioactive compound in living organisms: Itaconic acid inhibits the glyoxylate shunt essential for many bacteria to survive during infection $(59,75)$. The activation of the glyoxylate shunt is a survival strategy of invading pathogens, allowing them to utilize acetyl-CoA-generating carbon sources such as fatty acids or cholesterol for biomass production under glucose-limiting conditions (51). As an example, this metabolic mechanism is required for persistence of the pathogens Salmonella enterica and Mycobacterium tuberculosis within macrophages, but it is not essential for acute-phase infections $(28,51,61)$.

The glyoxylate shunt is an anabolic variation of the TCA cycle (see Figure 2). In contrast to the net decarboxylation of acetyl-CoA in the TCA cycle, the glyoxylate shunt preserves the carbon atoms of acetyl-CoA by bypassing the two decarboxylation steps. Isocitric acid is converted to glyoxylic acid and succinic acid, a reaction catalyzed by isocitrate lyase (ICL). Malate synthase further converts glyoxylic acid and another acetyl-CoA molecule to malic acid (24, 84).

Itaconic acid inhibits ICL, the key enzyme of the glyoxylate shunt, and, in turn, the glyoxylate shunt itself. It functions as a competitive inhibitor, competing with succinic acid (60), presumably by binding to the active site of the enzyme. Although ICL and the glyoxylate shunt are present in many bacteria, archaea, plants, fungi, and protists, there is controversy over whether they are present in vertebrates (24). Because of its exclusive presence in microbes, this shunt has an important role as a potential drug target (69).

\subsection{Itaconic Acid Inhibits Bacterial Growth}

In 2011, Shin et al. (86) detected the presence of itaconic acid in the lung tissue of M. tuberculosisinfected mice, but they hypothesized that this metabolite was synthesized by the bacteria and not by the host. Conversely, Michelucci et al. (64) recently demonstrated that following bacterial

www.annualreviews.org • Itaconic Acid as a Mammalian Antimicrobial Metabolite
Glyoxylate shunt: anabolic pathway that allows growth on $\mathrm{C}_{2}$ compounds by bypassing the decarboxylation steps of the TCA cycle

ICL: isocitrate lyase 


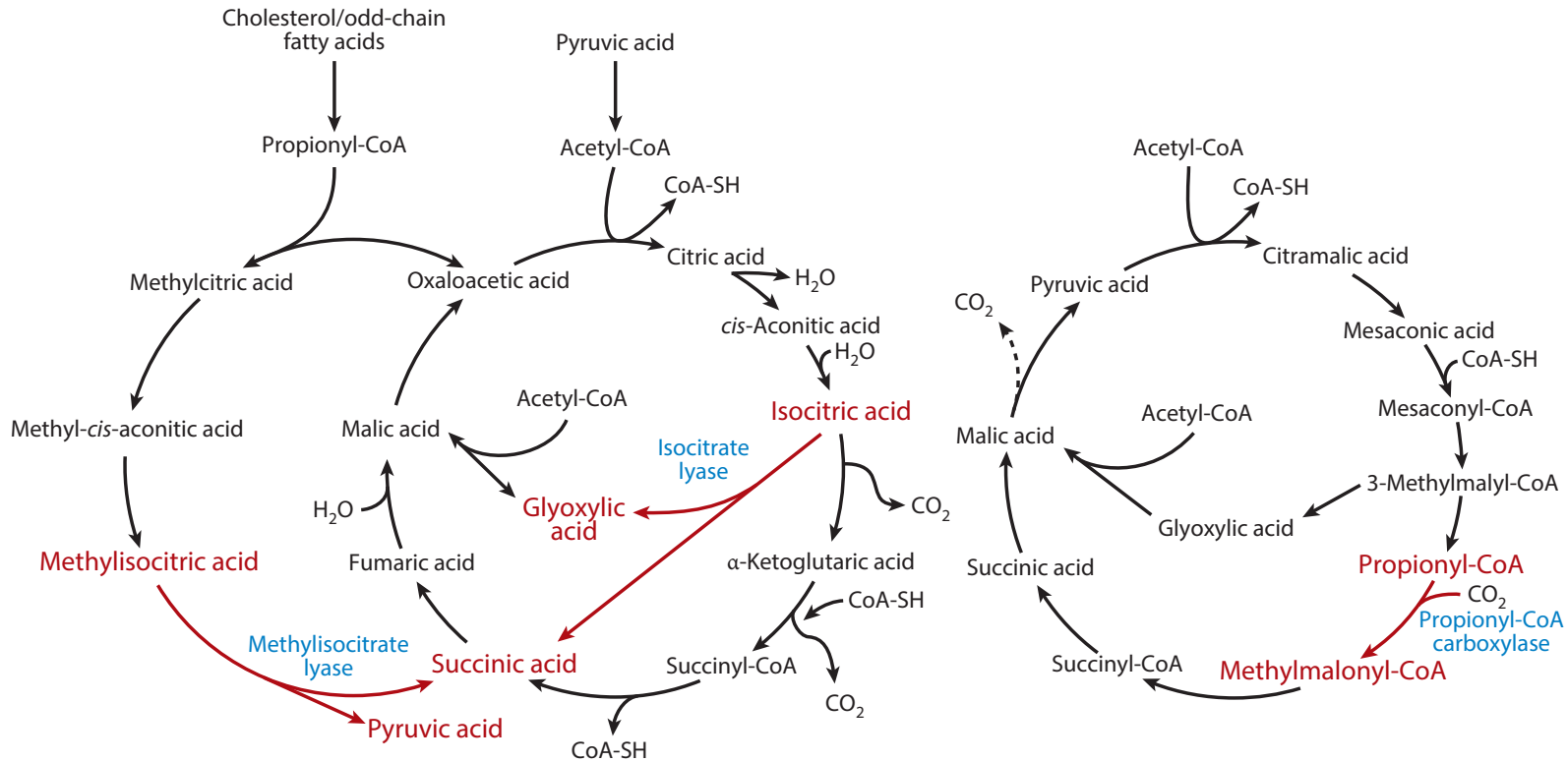

2-Methylcitrate cycle Methylisocitrate lyase

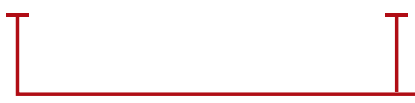

Glyoxylate shunt Isocitrate lyase
Citramalate cycle

Propionyl-CoA carboxylase

Itaconic acid

Figure 2

Antimicrobial activity: itaconic acid mode of action on pathogen metabolism. Itaconic acid is an inhibitor of isocitrate lyase, the key enzyme of the glyoxylate shunt. Because isocitrate lyase has an additional methylisocitrate lyase activity in Mycobacterium tuberculosis, itaconic acid also inhibits this 2-methylcitrate cycle in these bacteria. The inhibition of propionyl-CoA carboxylase by itaconic acid arrests the citramalate cycle in the proteobacterium Rhodospirillum rubrum. Enzymes inhibited by itaconic acid are in blue type, and inhibited biochemical pathways are in red.

Phagosome: cellular compartment formed by the fusion of the cell membrane inside which pathogenic microorganisms are killed and digested

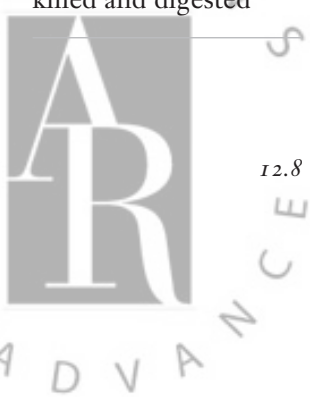

infection, mammalian immune cells, such as macrophages, produce large intracellular amounts of itaconic acid with concentrations around $8 \mathrm{mmol} \cdot \mathrm{l}^{-1}$ (see Section 5). The authors experimentally demonstrated the antimicrobial activity of itaconic acid and its role during immune defense against invading pathogens. Supplementation of $25-50 \mathrm{mmol} \cdot 1^{-1}$ itaconic acid to the bacterial growth medium fully inhibits the growth of the pathogen $M$. tuberculosis, whereas $10 \mathrm{mmol} \cdot \mathrm{l}^{-1}$ is sufficient to impair the growth of S. enterica (64). The purpose behind these high itaconic acid levels inside the immune cells is to combat against invading pathogens by inhibiting their ICL activity and, in turn, their growth. ICL activity is essential for the pathogens Mycobacterium avium and M. tuberculosis when growing on acetic acid or palmitic acid as carbon sources (40).

From a different point of view, ICL is a persistence factor in Burkbolderia pseudomallei. The inhibition of ICL by itaconic acid switches infections in rats to an acute state. Thus, itaconic acid "wakes up" pathogens. With this strategy, itaconic acid does not directly inhibit the growth of the pathogen but rather enables a starting point for a further treatment with antibiotics to inhibit the pathogens' growth (102).

In addition to ICL, itaconic acid also inhibits other enzyme functions and, in turn, affects metabolic pathways, including the 2-methylcitrate cycle (see Figure 2). Invading pathogens, such

Cordes • Michelucci $\bullet$ Hiller 
as $M$. tuberculosis, use cholesterol from the host as a carbon source due to limited glucose availability in phagosomes $(74,79)$. During the last step of cholesterol degradation, propionyl-CoA, which is also the final product of odd-chain fatty acid oxidation, is produced. Since propionyl-CoA is toxic for the pathogens $(8,99)$, they detoxify this metabolite to succinic acid and pyruvic acid using the 2 -methylcitrate cycle. The first reaction is catalyzed by methylisocitrate lyase (MCL), which is very similar to ICL (100). In this context, it is intriguing that both ICL isoforms of M. tuberculosis also exhibit MCL activity and are essential for propionyl-CoA detoxification in these bacteria (68).

Indeed, we demonstrated that itaconic acid inhibits the growth of M. tuberculosis within macrophages by interfering with the above-mentioned pathways: first, inhibition of MCL activity leads to the inhibition of propionic acid detoxification; second, the inhibition of ICL leads to the inability of the bacteria to generate biomass through the glyoxylate shunt (see Figure 2). Itaconic acid exhibits a dual inhibition on bacterial enzymes, thus playing a prominent role as an endogenous antimicrobial compound (64).

\subsection{Itaconic Acid Inhibits the Citramalate Cycle}

Interestingly, itaconic acid also inhibits propionyl-CoA carboxylase, an enzyme that carboxylizes propionyl-CoA to methylmalonyl-CoA in the citramalate cycle (see Figure 2) (8). This cycle is an anaplerotic pathway proposed for the proteobacterium Rhodospirillum rubrum, which lacks ICL activity. The inhibition of propionyl-CoA carboxylase by itaconic acid leads to an inhibition of acetic acid and propionic acid assimilation in cell extracts of this bacterium. However, cell growth was not affected by supplementation of itaconic acid in the medium and, based on these observations, Berg et al. (8) suspected that the bacterium is either able to secrete itaconic acid or to detoxify it. Taken together, these findings demonstrate that itaconic acid can inhibit metabolic pathways in pathogens lacking the glyoxylate shunt and, thus, also ICL activity (see Figure 2).

\subsection{Bacteria Detoxify Itaconic Acid}

Recently, Sasikaran et al. (81) discovered that many pathogens have developed defense mechanisms to detoxify itaconic acid, including Yersinia pestis and Pseudomonas aeruginosa. The degradation and detoxification of itaconic acid in these invading pathogens is catalyzed by three recently identified genes: itaconate coenzyme A transferase ( Ict), itaconyl CoA hydratase (Ich), and (S)citramalyl-CoA lyase $(\mathrm{Ccl})$. The combined action of these enzymes finally degrades itaconic acid to acetyl-CoA and pyruvic acid. All of these enzymes are essential for the survival of Yersinia pestis within host organisms and were described long before their importance for itaconic acid degradation was elucidated. Thus, the three-gene cluster was named "required for intracellular proliferation" (ripABC) (63). This pathway is in line with the previously reported degradation pathway in mammalian mitochondria (see Section 5) $(2,104)$ and with the previous observations of Berg et al. (8). As discussed in Section 4.3, the authors observed that itaconic acid does not affect the growth of Rhodospirillum rubrum, although it inhibits the citramalate cycle. However, they could not discover the bacterial itaconic acid degradation pathway and the involved enzymes. The production of itaconic acid in macrophages and subsequent pathogen adaptation to this antimicrobial compound are highlighted in Figure 3.

Interestingly, homologues of this three-gene cluster are also present in many other pathogens, including Yersinia pseudotuberculosis, S. enterica, Burkholderia mallei, Mycoplasma synoviae, and Legionella longbeachae. Thus, these pathogenic bacteria possibly also exhibit the ability to detoxify and metabolize itaconic acid. In fact, it has been shown that Salmonella and Pseudomonas are able to take up itaconic acid from the medium and to incorporate carbon atoms derived from this metabolite

www.annualreviews.org • Itaconic Acid as a Mammalian Antimicrobial Metabolite

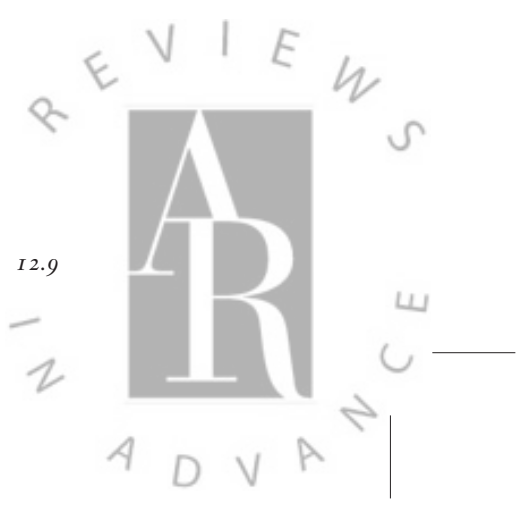




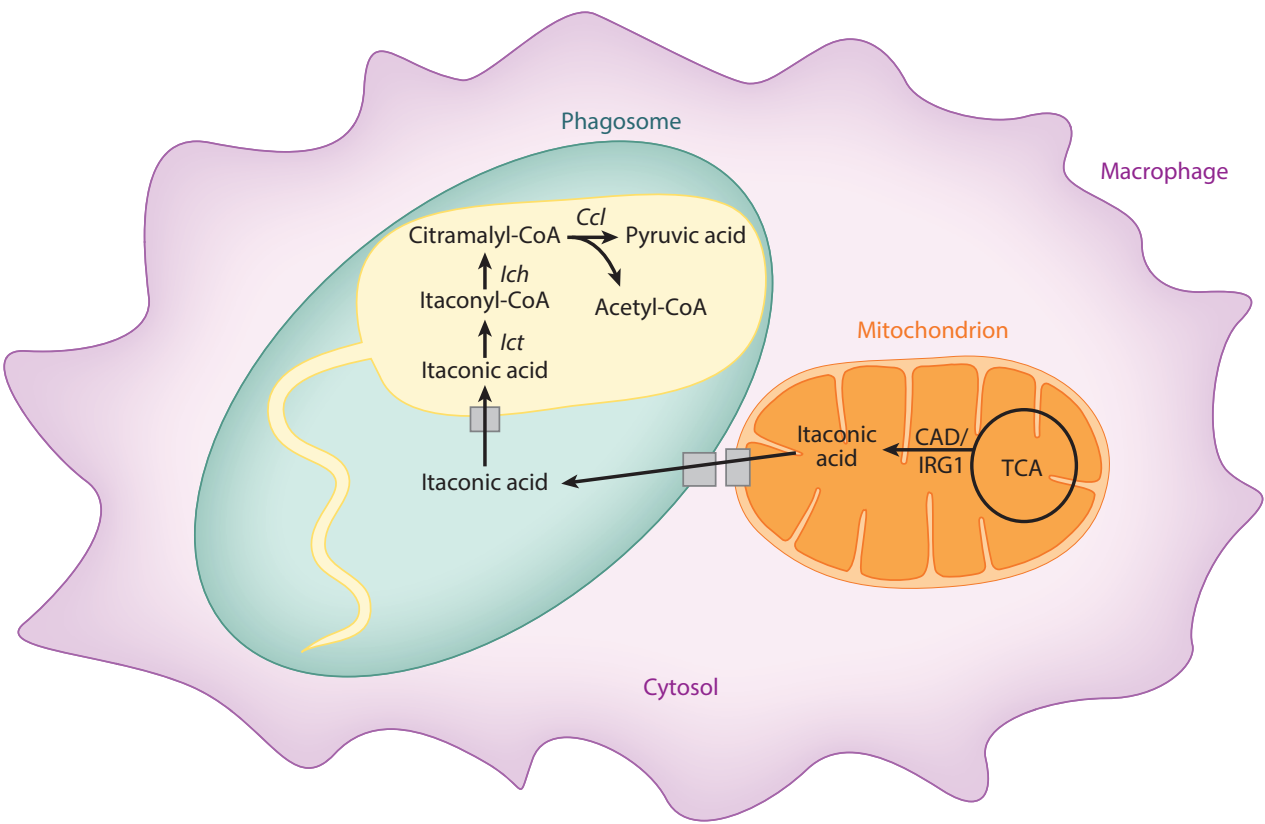

Figure 3

Production of itaconic acid in macrophages and adaptation of pathogens. Under inflammatory conditions, macrophages produce itaconic acid, catalyzed by CAD/IRG1. It might then be further transported from the mitochondrion into the phagosome and further taken up by invading pathogens through an as-yet-unknown transport mechanism. Some invading pathogens are able to detoxify itaconic acid by degrading this antimicrobial compound to pyruvic acid and acetyl-CoA. Abbreviations: CAD/IRG1, cis-aconitic acid decarboxylase/immune-responsive gene 1 protein; $C c l$, $(S)$-citramalyl-CoA lyase; Ich, itaconyl CoA hydratase; Ict, itaconate coenzyme A transferase; TCA, tricarboxylic acid.

(58). Since the itaconic acid degradation pathway is present in many bacteria, and it is an important persistence factor for pathogen survival inside macrophages, it represents a promising target for new antimicrobial drugs (81).

\section{ITACONIC ACID AND MAMMALIAN METABOLISM}

\subsection{The Discovery of Itaconic Acid and CAD Activity in Mammalian Cells}

The innate immune system is the first line of defense during infections. Cells of the innate immune system recognize pathogen-associated molecular patterns via pattern-recognition receptors, including Toll-like receptors (TLRs), which are present on the membrane and in the cytosol. Under resting conditions, cells of the innate immune system are immunologically inactive; however, upon recognition of foreign material, such as the bacterial endotoxin lipopolysaccharide (LPS), these cells have the ability to respond rapidly. To clear the infection, immune cells produce a wide array of mediators, including cytokines and chemokines, as well as antimicrobial metabolites.

To identify metabolites that are produced during the immune response, Sugimoto and colleagues (91) profiled the extracellular metabolites of LPS-activated macrophages. In this context, they discovered itaconic acid in the extracellular environment (91), but did not discuss its biological relevance. Only shortly later, high concentrations of itaconic acid in activated macrophages

Cordes $・$ Michelucci $\bullet$ Hiller 
were described by Strelko et al. (89), who first highlighted itaconic acid as a novel mammalian metabolite that most likely plays a role in macrophages during immune responses.

Following the discovery of itaconic acid in mammalian immune cells, its biosynthesis pathway was revealed using stable isotope-assisted metabolomics $(64,89)$. Incubation of LPS-activated macrophages with uniformly labeled $\left[\mathrm{U}_{-}{ }^{13} \mathrm{C}_{6}\right]$ glucose revealed that mammalian cells produce itaconic acid through decarboxylation of the TCA cycle intermediate cis-aconitic acid $(64,89)$, which is the same metabolic pathway as described for $A$. terreus (see Section 2). Two years later, we identified the enzyme catalyzing this decarboxylation: through a sequence homology search for $A s$ pergillus CAD, we found the mammalian IRG1 as the CAD homologue in mammals (64). Aspergillus CAD shows a $23 \%$ amino acid sequence identity to murine IRG1 and $25 \%$ identity to human IRG1. Murine and human IRG1 protein amino acid sequences are $84 \%$ identical. Furthermore, enzymatic assays with purified mammalian IRG1 and cis-aconitic acid as substrate showed itaconic acid production, finally confirming the CAD activity of IRG1 (64). Following the discovery of its enzymatic activity, IRG1 protein was recently renamed to CAD (UniProtKB/Swiss-Prot: mouse CAD-accession number P54987; human CAD-accession number A6NK06). To avoid confusion in the nomenclature of $\mathrm{CAD}$ proteins between Aspergillus and mammals, we refer to mammalian IRG1 protein as CAD/IRG1.

The CAD/IRG1 protein is encoded by immunoresponsive gene 1 (IRG1); its sequence has been mapped to mouse chromosome 14 (53), and its human homologue has been located to chromosome $13 \mathrm{q} 22.3$. Interestingly, the predicted mRNA sequence of the human IRG1 gene has been updated several times in the past few years (107), and we have confirmed that only the most recently published sequence (RefSeq NM_001258406.1) codes for a functional CAD/IRG1 (64).

\subsection{IRG1 Gene Expression in Mammalian Cells}

In 1995, $\operatorname{Irg} 1$ transcript was isolated for the first time from a cDNA library prepared from endotoxin-stimulated murine macrophages (53). Later, $\operatorname{Irg} 1$ upregulation was observed in murine macrophages infected with Mycobacteria $(3,85)$ or S. enterica (64) as well as in LPS-stimulated bone marrow-derived dendritic cells (41). IRG1 expression has also been detected in human fetal peripheral blood mononuclear cells (PBMCs) and LPS-stimulated adult PBMCs (107) as well as in endotoxin-activated PBMC-derived macrophages (64). In addition, IRG1 is highly upregulated in PBMCs of septic patients (55).

Besides peripheral immune cells, Irg1 expression has also been observed in murine microglial cells, which are macrophage analogues of the central nervous system. In these cells, Irg1 expression is upregulated in vivo after infection with Toxoplasma gondii (54) and in vitro after LPS stimulation (97).

Irg1 expression has been detected in the lung tissue of mice during the early phase of influenza A virus infection (77) and in chickens infected with Marek's disease (87). Given the enzymatic function of CAD/IRG1 to produce the antimicrobial compound itaconic acid, it is intriguing that its expression can also be induced during viral infections, since viruses do not possess a proper metabolism toward which itaconic acid could potentially interfere. The observed IRG1 induction during viral infections suggests an additional function of CAD/IRG1, independent of itaconic acid production.

In a recent study, $\operatorname{Irg} 1$ expression was increased after infection with neurotropic viruses. In this analysis, $\operatorname{Irg} 1$ expression was unexpectedly detected in cells that do not belong to the immune system, namely in granule cell neurons of the cerebellum and in cortical neurons from the cerebral cortex. Different Irg1 expression levels in these two types of neurons have been linked to differential susceptibility to viral infections (17).

www.annualreviews.org • Itaconic Acid as a Mammalian Antimicrobial Metabolite

\section{CAD/IRG1:}

mammalian CAD

(cis-aconitic acid

decarboxylase)

previously known as

immune-responsive

gene 1 protein

PBMC: peripheral blood mononuclear cell

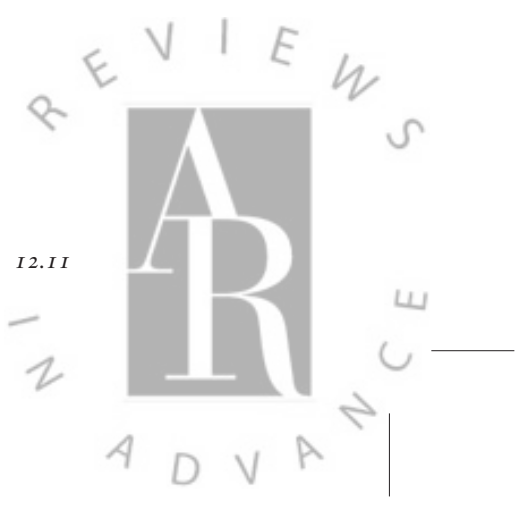


ROS: reactive oxygen species
Finally, independently from pathogenic conditions such as bacterial or viral infections, an upregulation of $\operatorname{Irg} 1$ expression has been detected in the early events leading to implantation in the pregnant uterus $(15,16,96)$. In this phase, a high level of inflammatory cytokines is secreted by the endometrial cells as well as by cells of the immune system, which are recruited to the site of implantation (66). Thus, it seems that $\operatorname{Irg} 1$ expression contributes to this immune response, probably producing high levels of itaconic acid as an antimicrobial compound.

Taken together, these results demonstrate that IRG1 expression is related to infectious and inflammatory conditions and point toward the importance of CAD/IRG1 contributing to the immune response.

\subsection{IRG1 Posttranscriptional Stability and CAD/IRG1 Regulation}

The stability of $\operatorname{Irg} 1 \mathrm{mRNA}$ is dependent on the type of infection. An analysis of posttranscriptional regulation revealed that $\operatorname{Irg} 1 \mathrm{mRNA}$ stability was increased in LPS-stimulated macrophages when compared to Mycobacterium avium infections (3). The control of mRNA stability is a crucial point of gene expression regulation. A common element responsible for the modulation of mRNA decay is the adenine- and uracil- (AU)-rich element in the $3^{\prime}$ untranslated region (UTR) of target mRNAs $(13,82)$. With its AU-rich elements in the $3^{\prime}$-UTR, Irg1 expression can be modulated by this mechanism (3). Interestingly, inhibition of eukaryotic protein synthesis by cycloheximide increased Irg1 mRNA stability in M. avium-infected macrophages. This could indicate the presence of asyet-unknown factors destabilizing $\operatorname{Irg} 1 \mathrm{mRNA}(3)$.

At the protein level, sequence analysis identified putative cyclic adenosine monophosphatedependent phosphorylation sites and many putative protein kinase $\mathrm{C}$ phosphorylation sites near the C-terminus. Thus, CAD/IRG1 protein may be regulated at this level (53). However, detailed investigations of CAD/IRG1 protein regulation at the phosphorylation level are still pending.

\subsection{Subcellular Localization of Mammalian CAD/IRG1}

In contrast to its cytoplasmic localization in Aspergillus (see Section 2), mammalian CAD/IRG1 has been shown to colocalize with MitoTracker Green FM, a fluorescent compound that accumulates specifically in mitochondria (22). These observations were validated by cell fractionation experiments, in which CAD/IRG1 was found only in stimulated cells, and the vast majority was in the mitochondrial fraction. This is of special interest because CAD/IRG1 does not contain a known mitochondrial-targeting peptide (22). On the other hand, it has been shown that CAD/IRG1 contains consensus sequences for glycosaminoglycan (GAG attachment site), a sequence motif that is characteristic for many secreted cytokines and growth factors (94). Since CAD/IRG1 contains the GAG motif, it may function similarly to a cytokine and be consequently secreted (53). In favor of this hypothesis, a recent study that analyzed the secretome of immune cells revealed that mammalian CAD is among 775 detected proteins that were released by macrophages upon TLR4 induction (62). However, because highly sensitive measurements were used in this study, proteins that originate from leaking or dying cells could also have been identified. We could not detect CAD/IRG1 in the medium of LPS-activated macrophages by Western blot (unpublished data).

In support of the mitochondrial localization of CAD/IRG1, further studies have recently suggested additional functions of this protein linked to mitochondria. Investigators using zebrafish (Danio rerio) as an animal model have demonstrated that CAD/IRG1 augments bactericidal activity of macrophages by regulating $\beta$-oxidation-dependent mitochondrial reactive oxygen species (ROS) production (35). Fatty acid $\beta$-oxidation is a multistep process by which fatty acids are broken down to acetyl-CoA to produce energy through the TCA cycle and oxidative

Cordes - Michelucci $\bullet$ Hiller 
phosphorylation. As a by-product of oxidative phosphorylation, mitochondria produce superoxide, a ROS, through electrons leaking from the electron transport chain (83). Hall et al. (35) showed that in zebrafish, fatty acid supplementation can enhance mitochondrial ROS production in response to infection in an $\mathrm{irg} 1$-dependent manner. In a subsequent study by the same group, again in a zebrafish model, a similar mechanism has been described in epidermal cells. These cells utilize fatty acid $\beta$-oxidation to participate in the immune response during cutaneous inflammation. This mechanism also requires the activity of irg1-like, a second zebrafish homologue of the mammalian $\operatorname{Irg} 1$ (36). ROS species can function as signaling molecules to regulate the transcription and activity of various inflammatory mediators, including matrix metalloproteinases (70, 92), which contribute to macrophage recruitment during inflammatory processes of the skin (36). However, the mechanisms discovered in these studies have not yet been confirmed in mammalian cells.

Due to the importance of CAD/IRG1 in the immune-metabolism cross talk, it is plausible to think that further functions will be elucidated soon. At present, it is not known if these functions are accomplished directly by CAD/IRG1 or if in reality they are mediated by its product, itaconic acid.

\subsection{Itaconic Acid Secretion and Metabolism in Mammalian Cells}

Although in the previous sections we focused on itaconic acid biosynthesis, its secretion and degradation in mammalian cells have also been the subject of a few studies.

At present, the ability of activated macrophages to secrete itaconic acid has been reported $(90,91)$. In line with this finding, itaconic acid has been found to be more abundant in the serum of pregnant women who subsequently developed diabetes when compared to controls with uncomplicated pregnancies. Therefore, the presence of itaconic acid may demonstrate a potential role of inflammation in early pregnancy in the development of gestational diabetes mellitus (21). However, at present this is the only study that describes itaconic acid as a potential serological biomarker for inflammation.

Once itaconic acid is released, itaconic acid degradation may occur in cell types other than macrophages. It has been known for a long time that mammals are able to metabolize itaconic acid in liver cells. This itaconic acid degradation pathway in soluble extracts of rat and guinea pig liver mitochondria was described in the $1960 \mathrm{~s}(2,104)$ following the observation that when fed to dogs, only $24 \%$ of supplied itaconic acid could be found in their urine (27). Liver cells express a sodium-dependent dicarboxylate transporter $(14,45)$, by which itaconic acid may be concentrated and subsequently degraded.

In this mammalian degradation pathway, itaconic acid is first activated to the corresponding CoA ester to itaconyl-CoA by succinyl-CoA synthetase. Subsequently, similar to bacteria (see Section 4), itaconyl-CoA is hydrated to $(S)$-citramalyl-CoA, which is then cleaved by $(S)$ citramalyl-CoA lyase into acetyl-CoA and pyruvic acid $(2,20)$. Interestingly, recent studies have identified a human gene annotated as CitE-like protein (CLYBL-HUMAN) that possesses (S)citramalyl-CoA lyase activity (81).

\subsection{Itaconic Acid Affects Energy Metabolism}

Itaconic acid inhibits rat liver phosphofructokinase 2, a key regulator of the glycolytic pathway. Phosphofructokinase 2catalyzes the phosphorylation of fructose-6-phosphate to fructose-2,6bisphosphate (80). Fructose-2,6-bisphosphate in turn allosterically activates phosphofructokinase 1 , which catalyzes the phosphorylation of fructose-6-phosphate to fructose-1,6-bisphosphate. Due

www.annualreviews.org • Itaconic Acid as a Mammalian Antimicrobial Metabolite

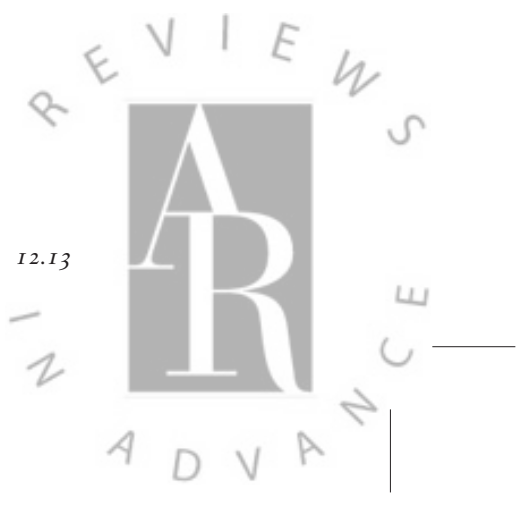


SDH: succinate dehydrogenase

M1 and M2 macrophages: classically M1 and alternatively M2 activated macrophages represent the extremes of a continuum of functional states; M1 macrophages exert antimicrobial activity, inhibit cell proliferation, and cause tissue damage, whereas M2 macrophages promote cell proliferation and tissue repair

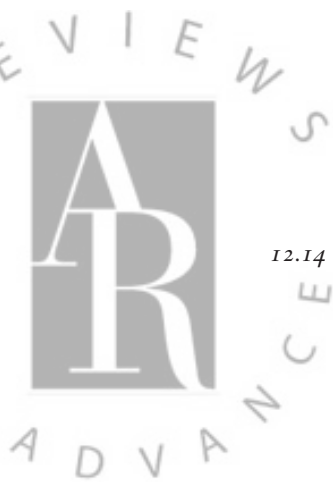

to the inhibition of the glycolytic pathway, it has been shown that itaconic acid suppresses the synthesis of fatty acids from glucose. In rats, an itaconic acid-enriched diet leads to a reduced visceral fat accumulation; therefore, itaconic acid could play a role in controlling obesity (80).

In addition to the inhibition of glycolysis, itaconic acid affects the TCA cycle. Like other TCA cycle intermediates, such as malic acid and oxaloacetic acid, itaconic acid has an inhibitory effect on succinate dehydrogenase $(\mathrm{SDH})(1,10,23)$. This enzyme complex binds to the inner mitochondrial membrane and oxidizes succinic acid to fumaric acid as part of the TCA cycle and in turn reduces flavin adenine dinucleotide (FAD) to $\mathrm{FADH}_{2}$, which feeds into the electron transport chain. Inhibition of SDH by itaconic acid should lead to accumulation of succinic acid in mitochondria. Indeed, recent findings show that LPS strongly increases succinic acid levels (95). On the other hand, several other causes, apart from SDH inhibition, could contribute to the accumulation of succinic acid. In a recent review by Mills \& O'Neill (65), two other possible sources are discussed. The first source is an increased glutamine uptake in LPS-activated macrophages and subsequent anaplerosis of $\alpha$-ketoglutaric acid into the TCA cycle, which may lead to increased succinic acid production. The second source is based on $\gamma$-aminobutyric acid (GABA), the production of which is induced by LPS. GABA can then be a substrate for succinic acid synthesis via transamination to succinic semialdehyde and subsequent oxidation (65).

\section{THE EMERGING CONCEPT OF METABOLIC IMMUNITY: THE INTERPLAY AMONG IMMUNITY, INFLAMMATION, AND METABOLISM}

\subsection{Metabolic Shifts in Immune Cells During Inflammation}

Metabolic adaptation of immune cells during health and disease states is a topic that is broad enough for its own review $(30,71,76)$. Here, we concisely describe the basic concepts, which illustrate how specific inflammatory processes and immune responses are characterized by significant changes in cellular metabolic activities (49). Emerging evidence highlights the important interplay between different inflammatory environments and the resulting metabolic shift of the immune cells. As an example, after exposure to TLR agonists, macrophages and dendritic cells switch to aerobic glycolysis in addition to oxidative phosphorylation $(50,78)$, similar to the Warburg effect displayed by cancer cells (103).

In their review, O'Neill \& Hardie (71) describe macrophage metabolic changes in detail, stating that increased ROS production in classically activated $(\mathrm{M} 1)$ cells $(33,67)$ occurs partly because of the attenuation of oxidative phosphorylation, whereas increased glycolytic flux is needed to maintain ATP levels for biosynthesis. As such, the production of nicotinamide adenine dinucleotide phosphate (NADPH) by the pentose phosphate pathway is favored. NADPH is the electron donor for NADPH oxidase, finally transferring electrons to molecular oxygen, thus producing the superoxide anion, a potent ROS species. Furthermore, mitochondria are recruited to phagolysosomes in a TNF receptor-associated factor 6 (TRAF6)-dependent fashion and produce ROS that are important for killing phagocytosed bacteria (see Section 5) $(76,105)$.

Conversely, alternatively activated (M2) macrophages (32) generate ATP mainly through oxidative phosphorylation in mitochondria. Since the electron transport is in this case not impaired, less ROS is leaking from the respiratory chain. This reflects the role of M2 macrophages in longer-term processes, such as tissue repair and antiparasitic effects $(29,71)$.

Modulations of particular metabolic pathways are able to influence and alter the acquisition of specific phenotypes. Recently, Choi and colleagues (18) demonstrated that inhibition of NADPH oxidase switched microglial activation, in response to an inflammatory challenge, from a classical to

Cordes $・$ Michelucci $\bullet$ Hiller 
an alternative state. Another example is the carbohydrate kinase-like protein (CARKL), which catalyzes the conversion of sedoheptulose into sedoheptulose-7-phosphate (37). CARKL-dependent metabolic reprogramming is required for proper M1 and M2 macrophage polarization.

\subsection{Metabolites as Antimicrobial Effectors and Inflammatory Signals}

The identification of metabolites playing an active role in the host immune response is a growing field of research. In the past, nitric oxide (NO), oxygen ions, and peroxides have been shown to exhibit antimicrobial properties, such as damaging microbial DNA. The essential substrate that drives NO production is the amino acid arginine, an intermediate of the urea cycle. The inducible nitric oxide synthase (iNOS) is activated by proinflammatory stimuli, such as interferon gamma $(\mathrm{IFN}-\gamma)$ or LPS, and catalyzes NO production from arginine, NADPH, and molecular oxygen (48). On the other hand, arginase is induced in alternatively activated cells, catalyzing arginine conversion into ornithine and subsequently into proline or polyamines, such as spermidin and spermin (19). Thus, arginine is a crucial amino acid that is differentially metabolized depending on the inflammatory environment (see Figure 4).

In contrast to NO or ROS, which act in a broad and unspecific way, itaconic acid has been shown to specifically and selectively act as an antimicrobial effector. Itaconic acid specifically inhibits ICL, the first enzyme of the glyoxylate shunt, an essential pathway for the survival of various bacteria during infection (see Section 4). In a similar context, it has recently been unveiled that increased levels of succinic acid following LPS exposure enhance interleukin-1 $\beta$ (IL-1 $\beta$ ) production through the stabilization of hypoxia-inducible factor 1 (95). Importantly, succinic acid is therefore acting as an inflammatory signal in activated macrophages.

Taken together, these observations highlight that itaconic acid, differently from ROS and $\mathrm{NO}$, acts as a specific antimicrobial metabolite that is generated by central carbon metabolism. Additionally, the tight cross talk between metabolism and the innate immune system through, for example, succinic acid accumulation is emphasized (see Figure 4). These recent findings are pointing toward a new, or at least revisited, field of research that we call metabolic immunity.

\section{CONCLUSION AND FUTURE DIRECTIONS}

In Figure 5, we highlight the history of itaconic acid, from its first discovery in 1836 to its detection as an endogenous mammalian antimicrobial compound in 2013. The discovery of its biosynthesis by the mammalian CAD/IRG1 enzyme has raised several questions on this newly characterized enzymatic reaction:

1. Industrial companies are highly interested in the optimization of itaconic acid production processes. Can the recently discovered mammalian CAD homologue outperform the classical fungal CAD itaconic acid production? Do kinetic parameters of the mammalian CAD/IRG1 differ from those of the fungal CAD and exhibit a higher affinity to its substrate?

2. Although the mammalian itaconic acid biosynthesis pathway has been recently revealed (64, 89), the relations of host and pathogen, including mammalian CAD/IRG1 and itaconic acid compartmentalization, as well as potential transport mechanism, are not yet understood. Since itaconic acid is produced in mitochondria in mammals, how is this metabolite transported into the phagosome and further taken up by invading pathogens?

3. Itaconic acid functions as an inhibitor of various enzymes, including ICL and SDH. As a result of this metabolic intervention, does itaconic acid formation under inflammatory

www.annualreviews.org • Itaconic Acid as a Mammalian Antimicrobial Metabolite
NO: nitric oxide

IFN- $\gamma$ : interferon gamma, a cytokine

IL-1 $\beta$ : interleukin-1 beta, a cytokine

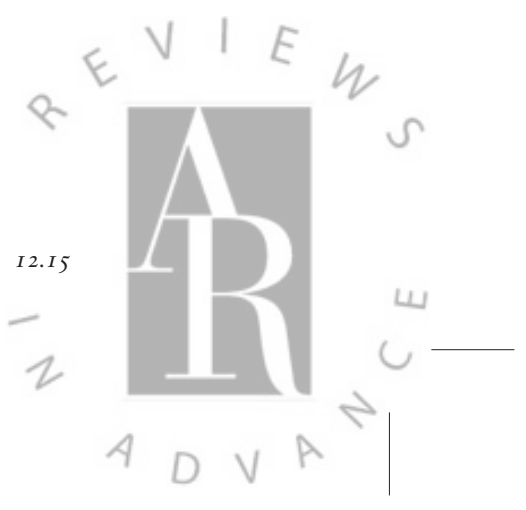


conditions lead to the accumulation of the TCA cycle intermediate succinic acid and induce further regulatory events?

In conclusion, the discovery of the surprising role of itaconic acid as an immune-supportive metabolite offers new intervention points for targeting infectious diseases. Itaconic acid synthesis is the first evidence of a highly specific mechanism disrupting microbial metabolism by immune cells. Furthermore, the enzymatic function of mammalian CAD/IRG1 has the potential to increase production yields in biotechnological processes.

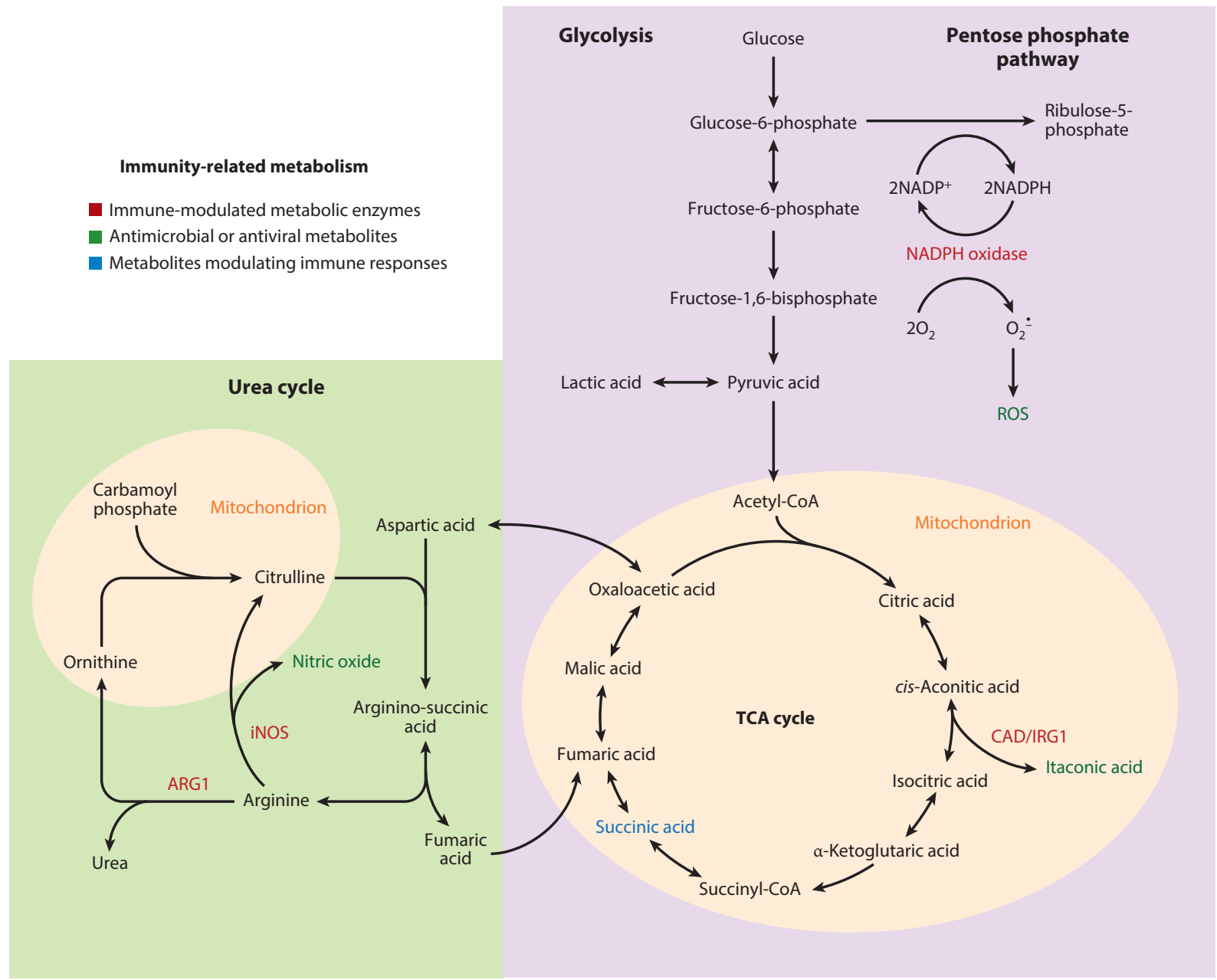

Figure 4

Selected examples of metabolic pathways and enzymes modulated under inflammatory conditions in mouse macrophages. Regulated enzymes (in red), metabolites possessing antimicrobial properties (in green), and metabolites known to play an active role in immune responses (in blue) are highlighted. Abbreviations: ARG1, arginase 1; CAD, cis-aconitic acid decarboxylase; iNOS, inducible nitric oxide synthase; IRG1, immune-responsive gene 1 protein; NADPH, nicotinamide adenine dinucleotide phosphate; ROS, reactive oxygen species; TCA, tricarboxylic acid.

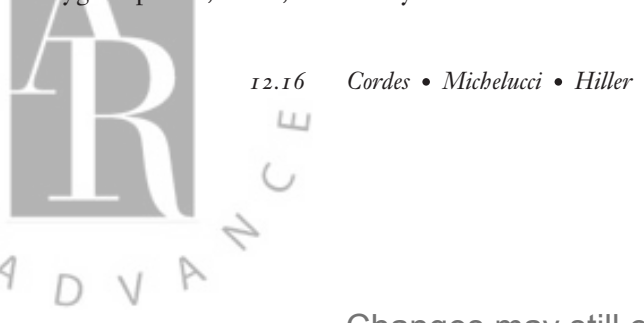




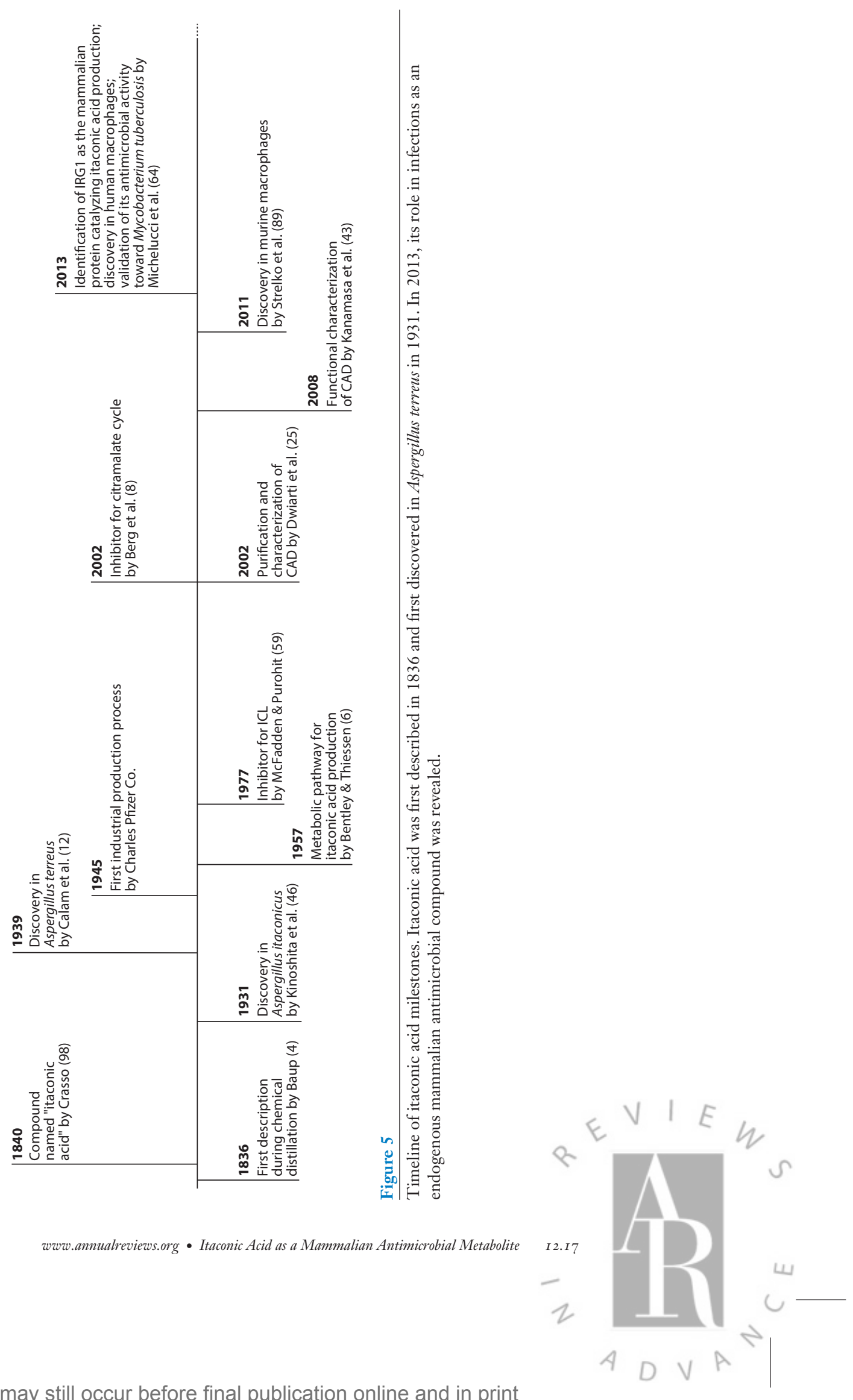




\section{SUMMARY POINTS}

1. Itaconic acid is biotechnologically produced by the fungus Aspergillus terreus and of high interest to industry for its use in polymer synthesis.

2. Itaconic acid is produced by the decarboxylation of the TCA cycle intermediate cisaconitic acid catalyzed by CAD/IRG1.

3. Itaconic acid plays an important role during inflammation and acts as an endogenously produced antimicrobial compound against pathogens.

4. Itaconic acid can inhibit microbial growth by interfering with enzymes of central metabolism, including the glyoxylate shunt, 2-methylcitrate cycle, and the TCA cycle.

5. Invading pathogens have developed a defense strategy to degrade and detoxify itaconic acid.

6. Itaconic acid acts as a specific antimicrobial metabolite that supports the cellular metabolic immune response.

\section{DISCLOSURE STATEMENT}

The authors are not aware of any affiliations, memberships, funding, or financial holdings that might be perceived as affecting the objectivity of this review.

\section{ACKNOWLEDGMENTS}

The authors would like to thank Dr. Alex Skupin, Dr. André Wegner, Daniel Weindl, and Sean Sapcariu for their insightful comments on the manuscript. This work was supported by the Fonds National de la Recherche, Luxembourg (ATTRACT A10/03).

\section{LITERATURE CITED}

1. Ackermann WW, Potter VR. 1949. Enzyme inhibition in relation to chemotherapy. Proc. Soc. Exp. Biol. Med. 72(1):1-9

2. Adler J, Wang S-F, Lardy HA. 1957. The metabolism of itaconic acid by liver mitochondria. F. Biol. Chem. 229(2):865-79

3. Basler T, Jeckstadt S, Valentin-Weigand P, Goethe R. 2006. Mycobacterium paratuberculosis, Mycobacterium smegmatis, and lipopolysaccharide induce different transcriptional and post-transcriptional regulation of the IRG1 gene in murine macrophages. F. Leukoc. Biol. 79(3):628-38

4. Baup S. 1836. Ueber eine neue pyrogen-citronensäure, und über benennung der pyrogen-säuren überhaupt. Ann. Pharm. 19(1):29-38

5. Bentley R, Thiessen CP. 1957. Biosynthesis of itaconic acid in Aspergillus terreus. III. The properties and reaction mechanism of cis-aconitic acid decarboxylase. 7. Biol. Chem. 226:703-20

6. Bentley R, Thiessen CP. 1957. Biosynthesis of itaconic acid in Aspergillus terreus. I. Tracer studies with $\mathrm{C}^{14}$-labeled substrates. 7. Biol. Chem. 226(2):673-87

7. Bercovitz A, Peleg Y, Battat E, Rokem JS, Goldberg I. 1990. Localization of pyruvate carboxylase in organic acid-producing Aspergillus strains. Appl. Environ. Microbiol. 56(6):1594-97

8. Berg IA, Filatova LV, Ivanovsky RN. 2002. Inhibition of acetate and propionate assimilation by itaconate via propionyl-CoA carboxylase in isocitrate lyase-negative purple bacterium Rhodospirillum rubrum. FEMS Microbiol. Lett. 216(1):49-54

Cordes • Michelucci • Hiller 
9. Bonnarme P, Gillet B, Sepulchre AM, Role C, Beloeil JC, Ducrocq C. 1995. Itaconate biosynthesis in Aspergillus terreus. F. Bacteriol. 177(12):3573-78

10. Booth AN, Taylor J, Wilson RH, Deeds F. 1952. The inhibitory effects of itaconic acid in vitro and in vivo. F. Biol. Chem. 195(2):697-702

11. Bressler E, Braun S. 2000. Conversion of citric acid to itaconic acid in a novel liquid membrane bioreactor. 7. Chem. Technol. Biotechnol. 75(1):66-72

12. Calam CT, Oxford AE, Raistrick H. 1939. Studies in the biochemistry of micro-organisms: itaconic acid, a metabolic product of a strain of Aspergillus terreus Thom. Biochem. F. 33(9):1488-95

13. Chen CY, Shyu AB. 1995. AU-rich elements: characterization and importance in mRNA degradation. Trends Biochem. Sci. 20(11):465-70

14. Chen X, Tsukaguchi H, Chen XZ, Berger UV, Hediger MA. 1999. Molecular and functional analysis of SDCT, a novel rat sodium-dependent dicarboxylate transporter. F. Clin. Invest. 103(8):1159-68

15. Cheng J, Che N, Li H, Ma K, Wu S, et al. 2013. Extraction, derivatization, and determination of metabolome in human macrophages. F. Sep. Sci. 36(8):1418-28

16. Cheon Y-P, Xu X, Bagchi MK, Bagchi IC. 2003. Immune-responsive gene 1 is a novel target of progesterone receptor and plays a critical role during implantation in the mouse. Endocrinology 144(12):562330

17. Cho H, Proll SC, Szretter KJ, Katze MG, Gale M, Diamond MS. 2013. Differential innate immune response programs in neuronal subtypes determine susceptibility to infection in the brain by positivestranded RNA viruses. Nat. Med. 19(4):458-64

18. Choi S-H, Aid S, Kim H-W, Jackson SH, Bosetti F. 2012. Inhibition of NADPH oxidase promotes alternative and anti-inflammatory microglial activation during neuroinflammation. F. Neurochem. 120(2):292 301

19. Classen A, Lloberas J, Celada A. 2009. Macrophage activation: classical versus alternative. Methods Mol. Biol. 531:29-43

20. Cooper RA, Kornberg HL. 1964. The utilization of itaconate by Pseudomonas sp. Biochem. 7. 91(1):8291

21. de Seymour JV, Conlon CA, Sulek K, Villas Bôas SG, McCowan LME, et al. 2014. Early pregnancy metabolite profiling discovers a potential biomarker for the subsequent development of gestational diabetes mellitus. Acta Diabetol. 51(5):887-90

22. Degrandi D, Hoffmann R, Beuter-Gunia C, Pfeffer K. 2009. The proinflammatory cytokine-induced IRG1 protein associates with mitochondria. F. Interferon Cytokine Res. 29(1):55-67

23. Dervartanian DV, Veeger C. 1964. Studies on succinate dehydrogenase. I. Spectral properties of the purified enzyme and formation of enzyme-competitive inhibitor complexes. Biochim. Biophys. Acta 92:23347

24. Dunn MF, Ramírez-Trujillo JA, Hernández-Lucas I. 2009. Major roles of isocitrate lyase and malate synthase in bacterial and fungal pathogenesis. Microbiology 155(Part 10):3166-75

25. Dwiarti L, Yamane K, Yamatani H, Kahar P, Okabe M. 2002. Purification and characterization of cis-aconitic acid decarboxylase from Aspergillus terreus TN484-M1. 7. Biosci. Bioeng. 94(1):29-33

26. El-Imam AA, Du C. 2014. Fermentative itaconic acid production. F. Biodivers. Bioprospect. Dev. 1(1):18

27. Emmrich R. 1939. Stoffwechselversuche mit einigen methylierten niedermolekularen dicarbonsäuren. Hoppe-Seyler's Zeitschrift für Physiol. Chemie 261(1-2):61-70

28. Fang FC, Libby SJ, Castor ME, Fung AM. 2005. Isocitrate lyase (acea) is required for Salmonella persistence but not for acute lethal infection in mice. Infect. Immun. 73(4):2547-49

29. Ghassabeh GH, De Baetselier P, Brys L, Noël W, Van Ginderachter JA, et al. 2006. Identification of a common gene signature for type II cytokine-associated myeloid cells elicited in vivo in different pathologic conditions. Blood 108(2):575-83

30. Ghesquière B, Wong BW, Kuchnio A, Carmeliet P. 2014. Metabolism of stromal and immune cells in health and disease. Nature 511(7508):167-76

31. Goncharov NV, Jenkins RO, Radilov AS. 2006. Toxicology of fluoroacetate: a review, with possible directions for therapy research. F. Appl. Toxicol. 26(2):148-61

www.annualreviews.org • Itaconic Acid as a Mammalian Antimicrobial Metabolite

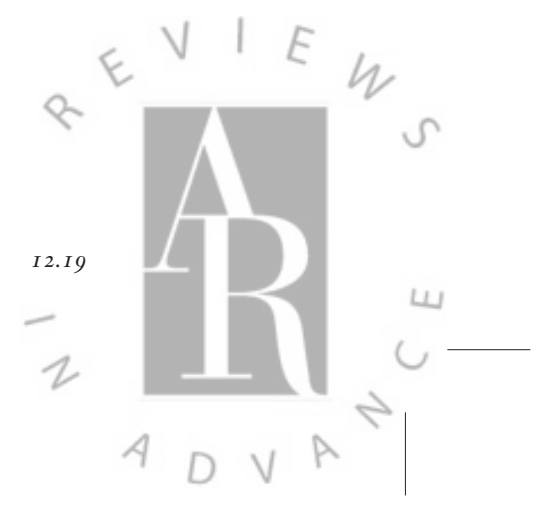


32. Gordon S. 2003. Alternative activation of macrophages. Nat. Rev. Immunol. 3(1):23-35

33. Gordon S, Martinez FO. 2010. Alternative activation of macrophages: mechanism and functions. Immunity 32(5):593-604

34. Gyamerah MH. 1995. Oxygen requirement and energy relations of itaconic acid fermentation by Aspergillus terreus NRRL 1960. Appl. Microbiol. Biotechnol. 44(1-2):20-26

35. Hall CJ, Boyle RH, Astin JW, Flores MV, Oehlers SH, et al. 2013. Immunoresponsive gene 1 augments bactericidal activity of macrophage-lineage cells by regulating $\beta$-oxidation-dependent mitochondrial ROS production. Cell Metab. 18(2):265-78

36. Hall CJ, Boyle RH, Sun X, Wicker SM, Misa JP, et al. 2014. Epidermal cells help coordinate leukocyte migration during inflammation through fatty acid-fuelled matrix metalloproteinase production. Nat. Commun. 5:3880

37. Haschemi A, Kosma P, Gille L, Evans CR, Burant CF, et al. 2012. The sedoheptulose kinase CARKL directs macrophage polarization through control of glucose metabolism. Cell Metab. 15(6):813-26

38. Haskins RHR, Thorn JA, Boothroyd B. 1955. Biochemistry of the Ustilaginales. XI. Metabolic products of Ustilago zeae in submerged culture. Can. 7. Microbiol. 1(9):749-56

39. Hevekerl A, Kuenz A, Vorlop K-D. 2014. Filamentous fungi in microtiter plates—an easy way to optimize itaconic acid production with Aspergillus terreus. Appl. Microbiol. Biotechnol. 98(16):6983-89

40. Höner zu Bentrup K, Miczak A, Swenson DL, Russell DG. 1999. Characterization of activity and expression of isocitrate lyase in mycobacterium avium and mycobacterium tuberculosis. F. Bacteriol. 181(23):7161-67

41. Hoshino K, Kaisho T, Iwabe T, Takeuchi O, Akira S. 2002. Differential involvement of IFN- $\beta$ in toll-like receptor-stimulated dendritic cell activation. Int. Immunol. 14(10):1225-31

42. Jaklitsch WM, Kubicek CP, Scrutton MC. 1991. The subcellular organization of itaconate biosynthesis in Aspergillus terreus. F. Gen. Microbiol. 137(3):533-39

43. Kanamasa S, Dwiarti L, Okabe M, Park EY. 2008. Cloning and functional characterization of the cisaconitic acid decarboxylase (CAD) gene from Aspergillus terreus. Appl. Microbiol. Biotechnol. 80(2):22329

44. Kautola H, Rymowicz W, Linko Y-Y, Linko P. 1991. Itaconic acid production by immobilized Aspergillus terreus with varied metal additions. Appl. Microbiol. Biotechnol. 35(2):154-58

45. Kekuda R, Wang H, Huang W, Pajor AM, Leibach FH, et al. 1999. Primary structure and functional characteristics of a mammalian sodium-coupled high affinity dicarboxylate transporter. 7 . Biol. Chem. 274(6):3422-29

46. Kinoshita K. 1931. Über eine neue Aspergillus-Art, Asp. itaconicus nov. spec. Bot. Mag. Tokyo 45:45-50

47. Klement T, Büchs J. 2013. Itaconic acid-a biotechnological process in change. Bioresour. Technol. $135: 422-31$

48. Knowles RG, Moncada S. 1994. Nitric oxide synthases in mammals. Biochem. 7. 298(Part 2):249-58

49. Kominsky DJ, Campbell EL, Colgan SP. 2010. Metabolic shifts in immunity and inflammation. 7. Immunol. 184(8):4062-68

50. Krawczyk CM, Holowka T, Sun J, Blagih J, Amiel E, et al. 2010. Toll-like receptor-induced changes in glycolytic metabolism regulate dendritic cell activation. Blood 115(23):4742-49

51. Kumar R. 2009. Glyoxylate shunt: combating mycobacterium at forefront. Int. F. Integr. Biol. 7(2):6972

52. Larsen BYH, Eimhjellen KE. 1954. The mechanism of itaconic acid formation by Aspergillus terreus. 1. The effect of acidity. Biochem. 7. 6:135-39

53. Lee Jenkins NA, Gilbert DJ, Copeland NG, O'Brien WE. 1995. Cloning and analysis of gene regulation of a novel LPS-inducible cDNA. Immunogenetics 41(5):263-70

54. Li H, Gang Z, Yuling H, Luokun X, Jie X, et al. 2006. Different neurotropic pathogens elicit neurotoxic CCR9- or neurosupportive CXCR3-expressing microglia. F. Immunol. 177(6):3644-56

55. Li Y, Zhang P, Wang C, Han C, Meng J, et al. 2013. Immune responsive gene 1 (IRG1) promotes endotoxin tolerance by increasing A20 expression in macrophages through ROS. F. Biol. Chem. 1(23):1622534

Cordes $\bullet$ Michelucci $\bullet$ Hiller 
56. Lin Y-H, Li Y-F, Huang M-C, Tsai Y-C. 2004. Intracellular expression of vitreoscilla hemoglobin in Aspergillus terreus to alleviate the effect of a short break in aeration during culture. Biotechnol. Lett. 26(13):1067-72

57. Maassen N, Panakova M, Wierckx N, Geiser E, Zimmermann M, et al. 2014. Influence of carbon and nitrogen concentration on itaconic acid production by the smut fungus Ustilago maydis. Eng. Life Sci. 14(2):129-34

58. Martin WR, Frigan F, Bergman EEH. 1961. Noninductive metabolism of itaconic acid by Pseudomonas and Salmonella species. F. Bacteriol. 82(6):905-8

59. McFadden BA, Purohit S. 1977. Itaconate, an isocitrate lyase-directed inhibitor in Pseudomonas indigofera. 7. Bacteriol. 131(1):136-44

60. McFadden BA, Williams JO, Roche TE. 1971. Mechanism of action of isocitrate lyase from Pseudomonas indigofera. Biochemistry 10(8):1384-90

61. McKinney JD, Höner zu Bentrup K, Muñoz-Elías EJ, Miczak A, Chen B, et al. 2000. Persistence of Mycobacterium tuberculosis in macrophages and mice requires the glyoxylate shunt enzyme isocitrate lyase. Nature 406(6797):735-38

62. Meissner F, Scheltema RA, Mollenkopf H-J, Mann M. 2013. Direct proteomic quantification of the secretome of activated immune cells. Science 340(6131):475-78

63. Ménage S, Attrée I. 2014. Pathogens love the poison. Nat. Chem. Biol. 10(5):326-27

64. Michelucci A, Cordes T, Ghelfi J, Pailot A, Reiling N, et al. 2013. Immune-responsive gene 1 protein links metabolism to immunity by catalyzing itaconic acid production. PNAS 110(19):7820-25

65. Mills E, O’Neill LAJ. 2014. Succinate: a metabolic signal in inflammation. Trends Cell Biol. 24(5):313-20

66. Mor G, Cardenas I, Abrahams V, Guller S. 2011. Inflammation and pregnancy: the role of the immune system at the implantation site. Ann. N. Y. Acad. Sci. 1221:80-87

67. Mosser DM. 2003. The many faces of macrophage activation. F. Leukoc. Biol. 73(2):209-12

68. Muñoz-Elias EJ. 2006. Mycobacterium tuberculosis isocitrate lyases 1 and 2 are jointly required for in vivo growth and virulence. Nat. Med. 11(6):638-44

69. Muñoz-Elías EJ, McKinney JD. 2006. Carbon metabolism of intracellular bacteria. Cell. Microbiol. $8(1): 10-22$

70. Nelson KK, Melendez JA. 2004. Mitochondrial redox control of matrix metalloproteinases. Free Radic. Biol. Med. 37(6):768-84

71. O'Neill LAJ, Hardie DG. 2013. Metabolism of inflammation limited by AMPK and pseudo-starvation. Nature 493(7432):346-55

72. Okabe M, Lies D, Kanamasa S, Park EY. 2009. Biotechnological production of itaconic acid and its biosynthesis in Aspergillus terreus. Appl. Microbiol. Biotechnol. 84(4):597-606

73. Okabe M, Ohta N, Park YS. 1993. Itaconic acid production in an air-lift bioreactor using a modified draft tube. F. Ferment. Bioeng. 76(2):117-22

74. Pandey AK, Sassetti CM. 2008. Mycobacterial persistence requires the utilization of host cholesterol. PNAS 105(11):4376-80

75. Patel TR, McFadden BA. 1978. Caenorhabditis elegans and Ascaris suum: inhibition of isocitrate lyase by itaconate. Exp. Parasitol. 44(2):262-68

76. Pearce EL, Pearce EJ. 2013. Metabolic pathways in immune cell activation and quiescence. Immunity 38(4):633-43

77. Preusse M, Tantawy MA, Klawonn F, Schughart K, Pessler F. 2013. Infection- and procedure-dependent effects on pulmonary gene expression in the early phase of influenza A virus infection in mice. $B M C$ Microbiol. 13:293

78. Rodríguez-Prados J-C, Través PG, Cuenca J, Rico D, Aragonés J, et al. 2010. Substrate fate in activated macrophages: a comparison between innate, classic, and alternative activation. F. Immunol. 185(1):605-14

79. Russell DG, Vanderven BC, Lee W, Abramovitch RB, Homolka S, et al. 2010. Mycobacterium tuberculosis wears what it eats. Cell Host Microbe 8(1):68-76

80. Sakai A, Kusumoto A, Kiso Y, Furuya E. 2004. Itaconate reduces visceral fat by inhibiting fructose 2,6-bisphosphate synthesis in rat liver. Nutrition 20(11-12):997-1002

81. Sasikaran J, Ziemski M, Zadora PK, Fleig A, Berg IA. 2014. Bacterial itaconate degradation promotes pathogenicity. Nat. Chem. Biol. 10:371-77

www.annualreviews.org • Itaconic Acid as a Mammalian Antimicrobial Metabolite

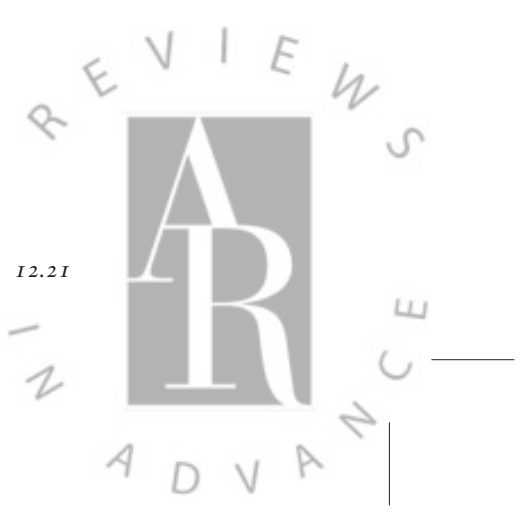


82. Schiavone N, Rosini P, Quattrone A, Donnini M, Lapucci A, et al. 2000. A conserved AU-rich element in the $3^{\prime}$ untranslated region of bcl-2 mRNA is endowed with a destabilizing function that is involved in bcl-2 down-regulation during apoptosis. FASEB 7. 14(1):174-84

83. Sena LA, Chandel NS. 2012. Physiological roles of mitochondrial reactive oxygen species. Mol. Cell 48(2):158-67

84. Sharma V, Sharma S, Hoener K, McKinney JD, Russell DG, et al. 2000. Structure of isocitrate lyase, Mycobacterium tuberculosis. Nat. Struct. Biol. 7(8):663-68

85. Shi S, Blumenthal A, Hickey CM, Gandotra S, Levy D, Ehrt S. 2005. Expression of many immunologically important genes in Mycobacterium tuberculosis-infected macrophages is independent of both TLR2 and TLR4 but dependent on IFN- $\alpha \beta$ receptor and STAT1. F. Immunol. 175(5):3318-28

86. Shin J-H, Yang J-Y, Jeon B-Y, Yoon Y-JJ, Cho S-N, et al. 2011. ${ }^{1} \mathrm{H}$ NMR-based metabolomic profiling in mice infected with Mycobacterium tuberculosis. F. Proteome Res. 10(5):2238-47

87. Smith J, Sadeyen J-R, Paton IR, Hocking PM, Salmon N, et al. 2011. Systems analysis of immune responses in Marek's disease virus-infected chickens identifies a gene involved in susceptibility and highlights a possible novel pathogenicity mechanism. F. Virol. 85(21):11146-58

88. Steiger MG, Blumhoff ML, Mattanovich D, Sauer M. 2013. Biochemistry of microbial itaconic acid production. Front. Microbiol. 4:23

89. Strelko CL, Lu W, Dufort FJ, Seyfried TN, Chiles TC, et al. 2011. Itaconic acid is a mammalian metabolite induced during macrophage activation. F. Am. Chem. Soc. 133(41):16386-89

90. Strelkov S, von Elstermann M, Schomburg D. 2004. Comprehensive analysis of metabolites in Corynebacterium glutamicum by gas chromatography/mass spectrometry. Biol. Chem. 385(9):853-61

91. Sugimoto M, Sakagami H, Yokote Y, Onuma H, Kaneko M, et al. 2011. Non-targeted metabolite profiling in activated macrophage secretion. Metabolomics 8(4):624-33

92. Svineng G, Ravuri C, Rikardsen O, Huseby N-E, Winberg J-O. 2008. The role of reactive oxygen species in integrin and matrix metalloproteinase expression and function. Connect. Tissue Res. 49(3):197-202

93. Tabuchi T, Sigisawa T, Ishidori T, Nakahara T, Sugiyama J. 1981. Itaconic acid fermentation by a yeast belonging to the genus Candida. Agric. Biol. Chem. 45(2):475-79

94. Tanaka Y, Adams DH, Shaw S. 1993. Proteoglycans on endothelial cells present adhesion-inducing cytokines to leukocytes. Immunol. Today 14(3):111-15

95. Tannahill GM, Curtis AM, Adamik J, Palsson-McDermott EM, McGettrick AF, et al. 2013. Succinate is an inflammatory signal that induces IL-1 $\beta$ through HIF-1 $\alpha$. Nature 496(7444):238-42

96. Terakawa J, Wakitani S, Sugiyama M, Inoue N, Ohmori Y, et al. 2011. Embryo implantation is blocked by intraperitoneal injection with anti-LIF antibody in mice. F. Reprod. Dev. 57(6):700-7

97. Thomas DM, Francescutti-Verbeem DM, Kuhn DM. 2006. Gene expression profile of activated microglia under conditions associated with dopamine neuronal damage. FASEB 7. 20(3):515-17

98. Turner E. 1840. Elements of Chemistry: Including the Recent Discoveries and Doctrines of the Science. Philadelphia: Cowperthwait \& Co.

99. Upton AM, McKinney JD. 2007. Role of the methylcitrate cycle in propionate metabolism and detoxification in Mycobacterium smegmatis. Microbiology 153(Part 12):3973-82

100. Van der Geize R, Yam K, Heuser T, Wilbrink MH, Hara H, et al. 2007. A gene cluster encoding cholesterol catabolism in a soil actinomycete provides insight into Mycobacterium tuberculosis survival in macrophages. PNAS 104(6):1947-52

101. Van der Straat L, Vernooij M, Lammers M, van den Berg W, Schonewille T, et al. 2014. Expression of the Aspergillus terreus itaconic acid biosynthesis cluster in Aspergillus niger. Microb. Cell Fact. 13(1):11

102. Van Schaik EJ, Tom M, Woods DE. 2009. Burkholderia pseudomallei isocitrate lyase is a persistence factor in pulmonary melioidosis: implications for the development of isocitrate lyase inhibitors as novel antimicrobials. Infect. Immun. 77(10):4275-83

103. Vander Heiden MG, Cantley LC, Thompson CB. 2009. Understanding the Warburg effect: the metabolic requirements of cell proliferation. Science 324(5930):1029-33

104. Wang SF, Adler J, Lardy HA. 1961. The pathway of itaconate metabolism by liver mitochondria. F. Biol. Chem. 236:26-30

105. West AP, Brodsky IE, Rahner C, Woo DK, Erdjument-Bromage H, et al. 2011. TLR signalling augments macrophage bactericidal activity through mitochondrial ROS. Nature 472(7344):476-80

Cordes $\bullet$ Michelucci $\bullet$ Hiller 
106. Willke T, Vorlop KD. 2001. Biotechnological production of itaconic acid. Appl. Microbiol. Biotechnol. 56(3-4):289-95

107. Xiao W, Wang L, Xiao R, Wu M, Tan J, He Y. 2011. Expression profile of human immune-responsive gene 1 and generation and characterization of polyclonal antiserum. Mol. Cell Biochem. 353(1-2):177-87

108. Yahiro K, Takahama T, Jai S, Park Y, Okabe M. 1997. Comparison of air-lift and stirred tank reactors for itaconic acid production by Aspergillus terreus. Biotechnol. Lett. 19(7):619-21

109. Yahiro K, Takahama T, Park YS, Okabe M. 1995. Breeding of Aspergillus terreus mutant TN-484 for itaconic acid production with high yield. F. Ferment. Bioeng. 79(5):506-8

110. Zinchenko VP, Goncharov NV, Teplova VV, Kasymov VA, Petrova OI, et al. 2007. Interaction of intracellular signalling and metabolic pathways at inhibition of mitochondrial aconitase by fluoroacetate. Cell Tissue Biol. 1(6):541-50

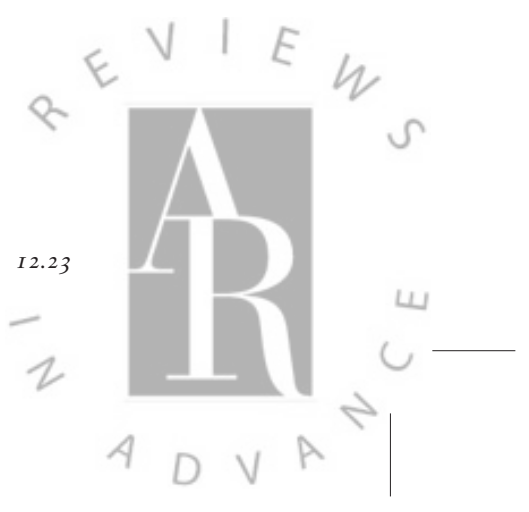

